\title{
Dynamic Connectedness of Uncertainty across Developed Economies: A Time-Varying Approach
}

\author{
Nikolaos Antonakakis ${ }^{1,2+}$, David Gabauer ${ }^{3}$, Rangan Gupta ${ }^{4}$, and Vasilios \\ Plakandaras 5
}

${ }^{1}$ Department of Business and Management, Webster Vienna Private University, Vienna, Austria, email: nikolaos.antonakakis@webster.ac.at

${ }^{2}$ Economics and Finance Subject Group, Portsmouth Business School, University of Portsmouth, Portland Street, Portsmouth, PO1 3DE, United Kingdom, e-mail: nikolaos.antonakakis@port.ac.uk

${ }^{3}$ Department of Business and Management, Webster Vienna Private University, Vienna, Austria, email: david.gabauer@ webster.ac.at

${ }^{4}$ Department of Economics, University of Pretoria, Pretoria, South Africa, email: Rangan.Gupta@up.ac.za

${ }^{5}$ Department of Economics, Democritus University of Thrace, Komotini, Greece, email: vplakand@econ.duth.gr

\begin{abstract}
Economic uncertainty has attracted a significant part of the modern research in economics, proving to be a significant factor for every economy. In this study, we focus on the transmission channel of uncertainty between developed economies, examining potential spillover effects between the U.S., the E.U., the U.K, Japan and Canada. Within a timevarying framework our empirical results indicate of a significant spillover of uncertainty from the E.U. to the U.S.
\end{abstract}

JEL codes: D80, E32, F42.

Keywords: Economic policy uncertainty, time-varying model, connectedness index

\footnotetext{
+ Corresponding author: Department of Business and Management, Webster Vienna Private University, Praterstraße 23, 1020, Vienna, Austria. Email: nikolaos.antonakakis@webster.ac.at, Tel: +4312699293 4354.
} 


\section{Introduction}

In wake of the "Great Recession", a large international literature has emerged that has analyzed the (negative) impact of uncertainty on macroeconomic variables and financial markets (see Chuliá et al., (2017) and Gupta et al., (forthcoming b) for detailed literature reviews). In parallel, numerous studies have also analyzed the spillover of uncertainty across economies (see, for example, Colombo (2013), Ajmi et al., (2014), Klößner and Sekkel (2014), Yin and Han (2014), Gupta et al., (2016, forthcoming a), Biljanovska et al., (2017), Caggiano et al., (2017)). This is important, since if foreign country uncertainties do affect domestic uncertainty, the former is going to have an indirect effect on domestic uncertainty, and prolong its expected direct effects (due to a globalized world) on the domestic economy.

Against this backdrop, we revisit the issue of uncertainty spillovers associated with the U.S., the U.K., Canada, Japan and the E.U., and add to the literature along the following dimensions: (a) Unlike the rolling-window estimation of the popular Diebold and Yilmaz (2012) model to capture spillovers over time, we use a full-fledged time-varying parameter vector autoregressive (TVP-VAR) version as suggested by Antonakakis and Gabauer (2017). This improves the methodology of Diebold and Yilmaz (2012) substantially, because there is no need to arbitrarily set the rolling window-size and there is no loss of observations $^{1}$; (b) Unlike the above-mentioned studies that utilize low-frequency monthly data to analyse uncertainty spillovers, we rely on daily data on uncertainty. Given that uncertainty is considered to be a leading indicator of the macroeconomy (Balcilar et al., 2016), it makes more sense to analyse movements of uncertainty at a higher data frequency, so that the policy makers in the domestic economy know how to react to movements in the foreign uncertainties which are likely to affect the low frequency macroeconomic variables in the future; and, (c) Finally, given that economic decisions and economic variables (macroeconomic and financial) are likely to react differently to short-, medium-, and longrun movements of uncertainties (Barrero et al., 2017), using wavelet theory, we decompose the uncertainty data into its various frequencies, and then in turn, repeat the spillover

\footnotetext{
${ }^{1}$ In the Appendix, we report the results from the constant parameter VAR model estimated with a rolling window of 250 observations. The empirical findings are similar to those of the TVP-VAR model, but we do lose a year or so of information in the process.
} 
analysis for each frequency component across the countries considered. In sum, to the best of our knowledge, this is the first attempt to analyse spillovers of uncertainties within developed economies across both time and frequency dimensions.

The results of our empirical analysis reveal a significant uncertainty transmission from the E.U. to the U.S. Moreover, we detect a change in the spillover effects with the horizon they are associated with, given that in measurements of uncertainty changes in longer horizons tend to be attributed to external drivers of uncertainty.

The remainder of this study is organized as follows. Section 2 describes the empirical methodology employed. The empirical results of our analysis are presented in Section 3. Finally, Section 4 summarizes and concludes this study.

\section{Dynamic Connectedness based on a TVP-VAR model}

To explore the transmission mechanism in a time-varying fashion, we are using the methodology outlined in Antonakakis and Gabauer (2017). According to the Bayesian Information Criterion (BIC) we are employing a stationary TVP-VAR(1) with timevarying volatility

$$
\begin{aligned}
Y t & =\beta_{t} Y_{t-1}+\varepsilon_{t} & & \varepsilon_{t} \sim N\left(0, S_{t}\right) \\
\beta_{t} & =\beta_{t-1}+v_{t} & & v_{t} \sim N\left(0, R_{t}\right) \\
Y_{t} & =A_{t} \varepsilon_{t-1}+\varepsilon_{t} & &
\end{aligned}
$$

where $\boldsymbol{Y}_{t}, \boldsymbol{\varepsilon}_{t}$ and $\boldsymbol{v}_{t}$ are $N \times 1$ vectors and $A_{t}, S_{t}, \beta_{t}$ and $R t$ are $N \times N$ matrices. Equation (3) is the Wold representation of the system. The time-varying coefficients of the vector moving average (VMA) is the fundament of the connectedness index introduced by Diebold and Yilmaz (2012) using the generalized impulse response function (GIRF) and the generalized forecast error variance decomposition (GFEVD) developed by Koop et al. (1996) and Pesaran, and Shin (1998). Our focus is on the h-step error variance in forecasting variable $i$ that is due to shocks on variable $j$. Mathematically, it can be written as follows,

$$
\tilde{\varphi}_{i j, t}^{g}(h)=\frac{\sum_{t=1}^{h-1} \Psi_{i j, t}^{2, g}}{\sum_{i=1}^{N} \sum_{t=1}^{h-1} \Psi_{i j, t}^{2, g}}
$$


with $\tilde{\varphi}_{i j, t}^{g}(h)$ denotes the $h$-step ahead GFEVD, $\Psi_{i j, t}^{g}(h)=S_{i j, t}^{-\frac{1}{2}} A_{h, t} \Sigma_{t} \varepsilon_{i j, t}, \quad \Sigma_{t}$ the covariance matrix for the error $\varepsilon_{i j, t}$ and $\sum_{j=1}^{N} \tilde{\varphi}_{i j, t}^{g}(h)=1, \sum_{i, j=1}^{N} \tilde{\varphi}_{i j, t}^{N}(h)=N$. Based on the GFEVD, we construct the total connectedness index (TCI) representing the interconnectedness of the network, formulated by

$$
C_{t}^{g}(h)=\frac{\sum_{i, j=1, i \neq j}^{N} \widetilde{\varphi}_{i j, t}^{g}(h)}{\sum_{j=1}^{N} \widetilde{\varphi}_{i j, t}^{g}(h)} \times 100
$$

First, we are interested in the spillovers of variable $i$ to all others $j$, representing the total directional connectedness to others defined as

$$
C_{i \rightarrow j, t}^{g}(h)=\frac{\sum_{j=1, i \neq j}^{N} \widetilde{\varphi}_{j i, t}^{g}(h)}{\sum_{j=1}^{N} \widetilde{\varphi}_{j i, t}^{g}(h)} \times 100
$$

Second, we compute the spillovers of all variables $j$ to variable $i$, called the total directional connectedness from others defined as

$$
C_{i \leftarrow j, t}^{g}(h)=\frac{\sum_{j=1, i \neq j}^{N} \widetilde{\varphi}_{i j, t}^{g}(h)}{\sum_{i=1}^{N} \widetilde{\varphi}_{i j, t}^{g}(h)} \times 100
$$

Third, we calculate the differences between the total directional connectedness to others and total directional connectedness from others to get the net total directional connectedness $C_{i, t}^{g}$ :

$$
C_{i, t}^{g}(h)=C_{i \rightarrow j, t}^{g}(h)-C_{i \leftarrow j, t}^{g}(h)
$$

The sign of the net total directional connectedness illustrates if variable $i$ is driving the network $\left(C_{i, t}^{g}(h)>0\right)$ or driven by the network $\left(C_{i, t}^{g}(h)<0\right)$. Finally, we break down the net total directional connectedness to examine the bidirectional relationships by computing the net pairwise directional connectedness (NPDC),

$$
N P D C_{i j}(h)=\frac{\widetilde{\varphi}_{j i, t}^{g}(h)-\widetilde{\varphi}_{i j, t}^{g}(h)}{N} \times 100
$$

\section{Empirical results}

We compile a dataset of daily macroeconomic uncertainty indices from Scotti (2016) for the U.S., the U.K., Canada, Japan and the E.U. spanning the period May 15, 2003 to 
October 02, 2017 (based on data availability), which to the best of our knowledge is the only available dataset on daily macroeconomic uncertainties. ${ }^{2}$ The dataset is characterized by periods of constant values (as shown in the Figures A-1 in the Appendix), so we use first difference transformation (instead of first difference of logarithms) of the series to ensure stationarity. We keep the same forecasting horizon of $h=10$ as in Diebold and Yilmaz (2012).

Apart from the first-differenced data, we also decompose all series based on the maximal overlap discrete wavelet transform (Persival and Walden, 2000). Given that the wavelet approach decomposes a signal in the frequency and not in the time domain, the order of the components adheres to variations and trends over different time aggregation levels. Although we cannot identify exactly the aggregation level (i.e. daily, monthly etc.), the first components adhere more closely to short-run variations, while the last components describe long-run phenomena ${ }^{3}$.

In Figure 1 we show the total connectedness index of the TVP-VAR model for the firstdifferenced data, while Figures 2 and 3 report the net volatility connectedness and the NPDC, respectively.

\section{[Insert Figure 1 to Figure 3]}

As we observe from Figure 1, the total connectedness of the system varies over time. Large spikes are observed around 2004, 2008 and 2011, justifying the selection of a time-varying approach. Figure 2 reveals that the U.S. uncertainty is mostly driven by exogenous influences, while the opposite stands for the E.U. Uncertainty in the U.K. only episodically affects other countries' uncertainties, with the exception of a large outgoing spillover (peak) around 2011. This peak can be attributed to the recession of the British economy and the Eurozone crisis of that period. Canada is the most isolated economy in our sample (accounting for uncertainty changes due to domestic shocks) with the exception of a large change in uncertainty that was imported around 2004 from the E.U. In contrast Japan is mainly a transmitter of uncertainty, driving uncertainty changes to the other economies,

\footnotetext{
${ }^{2}$ Daily data on economic policy uncertainty has also been developed by Baker et al., (2016), but is restricted to only the U.S. and the U.K.

${ }^{3}$ All the decomposed series are reported in the Appendix.
} 
with a large exception around 2011. Interestingly, the 2011 Eurozone crisis seems to have driven a change in uncertainty to the U.S., Japan and E.U. itself, but most of its source is located in the British economy, depicting the high level of connectivity of all economies globally.

The pairwise examination (Figure 3) corroborates to the aforementioned findings. Most of uncertainty spillovers to the U.S. stems from the E.U. and the U.K., while the E.U. "exports" uncertainty to the U.K. and "imports" from Japan. Canada is the mostly isolated with only episodically receiving uncertainty, and Japan is only episodically affected by the U.K. Overall, the paths of uncertainty spillovers demonstrate a closer link between the U.S. and the E.U.- an unlikely finding given the traditional relationships of the British economy with the U.S.

In Table 1, we repeat the aforementioned examination in a quantitative manner. The largest contribution to the U.S. economic uncertainty (3.1\%) comes from the Canadian economy, but that should be mainly attributed to the uncertainty spillover of the 2004 dot com bubble burst. The small value of the total volatility spillover (3.6\%) indicates that uncertainty spillovers over the entire sample are very small. In comparison to Biljanovska et al. (2017), our approach allows us not only to detect the existence of spillovers, but also to measure the significance of the spillover in the domestic economy.

\section{[Insert Table 1]}

We now turn to the examination of the uncertainty spillovers between the decomposed components (Table 2$)^{4}$.

\section{[Insert Table 2]}

As we observe from Panels A and B of Table 2, both the uncertainty effect originating from and to any given economy rise as we move from shorter to longer horizons, thus providing an indication that uncertainty spillovers between countries appear with a significant lag. Our findings corroborate the ones of Gupta et al. (2016) and Biljanovska et al. (2017), who also report such lagged effects. In Table 3, we report the total connectedness index for each component. Again the total connectedness of the system rises at longer horizons, reaching

\footnotetext{
${ }^{4}$ Detailed statistics and graphs are reported in the Appendix.
} 
up to $50.5 \%$ for the last components. This finding reflects that in the long-run most of the uncertainty variations should be attributed to exogenous influences, given that in the longrun the economy has time to adjust to any potential source of domestic uncertainty. In Figures 4 to 7, we depict the NPDC for the first, the second, the seventh and the eighth components in order to depict the uncertainty spillover in the short- and long-run.

[Insert Figure 4 to Figure 7]

The analyses of the Figures reveal the same pattern with the one from the qualitative presentation of Tables 2 and 3. Longer-span uncertainty changes in the U.S. tend to be "imported" from the E.U. and from the U.K., while on average the U.S. has a less pronounced effect on uncertainty changes in Canada. In the case of Japan, in the longerrun uncertainty changes tend to be influenced by the U.S. uncertainty and the E.U., while we observe uncertainty spillovers from Japan and the U.K. to the E.U. over certain time periods. Overall, we find that uncertainty spillovers tend to vary according to the time period and the horizon under examination.

\section{Concluding Remarks}

In this paper we study the existence of uncertainty spillovers between economies in a timevarying framework. In doing so, we study uncertainty changes using the dynamic connectedness index of Antonakakis and Gabauer (2017). Our empirical findings suggest a significant uncertainty transmission from the E.U. to the U.S. Moreover, we detect a change in the spillover effects with the horizon they are associated with, given that in measurements of uncertainty changes in longer horizons tend to be attributed to external drivers of uncertainty. While we restricted ourselves to analysis of macroeconomic uncertainty here, as part of future research, it would be interesting to analyze the spillovers across the various volatility indices (VIXs) involving financial markets of developed and developing countries, as well as commodity markets. 


\section{References}

Ajmi, A. N., Gupta, R., and Kanda, P.T. (2014). Causality between economic policy uncertainty across countries: Evidence from linear and nonlinear tests. Frontiers in Finance and Economics, 11, 73-102.

Antonakakis, N. and Gabauer, D. (2017). Refined Measures of Dynamic Connectedness based on TVP-VAR. MPRA Paper No. 78282.

Baker, S., Bloom, N., and and Davis, S.J. (2016): Measuring Economic Policy Uncertainty, Quarterly Journal of Economics, 131(4), 1539-1636.

Balcilar, M., Gupta, R., and Segnon, M. (2016). The Role of Economic Policy Uncertainty in Predicting U.S. Recessions: A Mixed-frequency Markov-switching Vector Autoregressive Approach. Economics: The Open-Access, Open-Assessment EJournal, 10, 1-20.

Barrero, J.M., Bloom, N., and Wright, I. (2017). Short and Long Run Uncertainty. NBER Working Paper No. 23676.

Biljanovska, N., Grigoli, F., and Hengge, M. (2017). Fear Thy Neighbor: Spillovers from Economic Policy Uncertainty, International Monetary Fund Working Papers series, No. 240

Caggiano, G., Castelnuovo, E., and Figueres, J.M. (2017). Economic Policy Uncertainty Spillovers in Booms and Busts, Melbourne Institute Working Paper No. 13/17.

Chuliá, H., Gupta, R., Uribe, J.M, Wohar, M.E. (2017). Impact of US Uncertainties on Emerging and Mature Markets: Evidence from a Quantile-Vector Autoregressive Approach. Journal of International Financial Markets Institutions \& Money, 48(C), 178-191.

Colombo, V. (2013). Economic policy uncertainty in the US: Does it matter for the Euro area? Economics Letters, 121, 39-42.

Diebold, F. X. and Yilmaz, K. (2012). Better to give than to receive: Predictive directional measurement of volatility spillovers. International Journal of Forecasting, 28(1):5766.

Gupta, R., Pierdzioch, C., and Risse M. (2015). On International Uncertainty Links: BART-Based Empirical Evidence for Canada Economics Letters, 143, 24-27.

Gupta, R., Lau, C-K-M., Wohar, M.E. (Forthcoming a). "The Impact of US Uncertainty on the Euro Area in Good and Bad Times: Evidence from a Quantile Structural Vector Autoregressive Model. Empirica. 
Gupta, R., Ma, J., Risse, M., and Wohar, M.E. (Forthcoming b). Common Business Cycles and Volatilities in US States and MSAs: The Role of Economic Uncertainty. Journal of Macroeconomics.

Klößner, S. and R. Sekkel (2014). International spillovers of policy uncertainty. Economics Letters, 124, 508-512.

Koop, G., Pesaran, M. H., and Potter, S. M. (1996). Impulse response analysis in nonlinear multivariate models. Journal of Econometrics, 74(1):119-147.

Percival, D. B., and A. T. Walden. Wavelet Methods for Time Series Analysis. Cambridge, UK: Cambridge University Press, 2000.

Pesaran, H. H., \& Shin, Y. (1998). Generalized impulse response analysis in linear multivariate models. Economics Letters, 58(1), 17-29.

Scotti, C. (2016). "Surprise and Uncertainty Indexes: Real-Time Aggregation of RealActivity Macro Surprises," Journal of Monetary Economics, 82, 1-19.

Yin, L. and L. Han (2014). Spillovers of macroeconomic uncertainty among major economies. Applied Economics Letters, 21, 938-944. 


\begin{tabular}{c|c|c|c|c|c|c}
\hline \hline \multicolumn{7}{c}{ Table 1: Uncertainty connectedness } \\
\hline & U.S. & E.U. & U.K. & Canada & Japan & FROM \\
\hline U.S. & 93.8 & 1.6 & 1 & 3.1 & 0.5 & 6.2 \\
E.U. & 1.2 & 96.8 & 0.8 & 0.7 & 0.5 & 3.2 \\
U.K. & 1 & 1.2 & 97 & 0.5 & 0.4 & 3 \\
Canada & 3 & 0.9 & 0.6 & 95.3 & 0.2 & 4.7 \\
Japan & 0.1 & 0.1 & 0.4 & 0.1 & 99.3 & 0.7 \\
\hline $\begin{array}{c}\text { Contribution } \\
\text { TO others }\end{array}$ & 5.2 & 3.8 & 2.9 & 4.3 & 1.5 & 17.8 \\
\hline $\begin{array}{c}\text { Contribution } \\
\text { including } \\
\text { own }\end{array}$ & 99 & 100.6 & 99.9 & 99.7 & 100.8 & \\
\hline $\begin{array}{c}\text { Net } \\
\text { spillovers }\end{array}$ & -1 & 0.6 & -0.1 & -0.3 & 0.8 & $\mathbf{3 . 6}$ \\
\hline \hline
\end{tabular}

Note: All values are percentages. The number in bold (bottom right corner) represents the total connectedness of the system. Its ijth entry is the estimated contribution to the forecast error variance of economy $i$ coming from innovations to economy $j$. The diagonal elements reveal self-inflicting uncertainty, while all the off-diagonal elements report spillover rates. 


\begin{tabular}{|c|c|c|c|c|c|}
\hline \multicolumn{6}{|c|}{ Table 2: Decomposed components - connectedness } \\
\hline $\begin{array}{l}\text { Component } \\
\text { /Horizon }\end{array}$ & U.S. & E.U. & U.K. & Canada & Japan \\
\hline \multicolumn{6}{|c|}{ Panel A: Contribution FROM others } \\
\hline 1 & 2.4 & 6.7 & 5.9 & 6.4 & 10.6 \\
\hline 2 & 4 & 7.9 & 6.9 & 8.1 & 9.8 \\
\hline 3 & 15.4 & 21.1 & 18.3 & 23.3 & 22.4 \\
\hline 4 & 27.3 & 28.2 & 28.3 & 30.8 & 31.4 \\
\hline 5 & 26 & 27.6 & 26.8 & 26.2 & 24.9 \\
\hline 6 & 28.2 & 30.3 & 26.5 & 31.4 & 33.2 \\
\hline 7 & 36.1 & 39.7 & 42.7 & 41.7 & 35.1 \\
\hline 8 & 48.7 & 55.1 & 47.9 & 53 & 47.9 \\
\hline \multicolumn{6}{|c|}{ Panel B: Contribution TO others } \\
\hline 1 & 4.7 & 5.8 & 5.1 & 8.6 & 7.7 \\
\hline 2 & 5.3 & 7.1 & 6.5 & 8.6 & 9 \\
\hline 3 & 18.3 & 22.3 & 18.6 & 22.6 & 18.7 \\
\hline 4 & 27 & 33.2 & 27.2 & 28.5 & 30.2 \\
\hline 5 & 22.6 & 28.1 & 27 & 29.4 & 24.5 \\
\hline 6 & 30.2 & 28.4 & 27.3 & 30.9 & 32.8 \\
\hline 7 & 38.6 & 40.1 & 43.7 & 42.4 & 30.7 \\
\hline 8 & 49.1 & 57.1 & 45.1 & 54.6 & 46.9 \\
\hline \multicolumn{6}{|c|}{ Panel C: Net Spillovers } \\
\hline 1 & 2.3 & -0.9 & -0.8 & 2.2 & -2.9 \\
\hline 2 & 1.3 & -0.8 & -0.4 & 0.5 & -0.8 \\
\hline 3 & 2.9 & 1.2 & 0.3 & -0.7 & -3.7 \\
\hline 4 & -0.3 & 5 & -1.1 & -2.3 & -1.2 \\
\hline 5 & -3.4 & 0.5 & 0.2 & 3.2 & -0.4 \\
\hline 6 & 2 & -1.9 & 0.8 & -0.5 & -0.4 \\
\hline 7 & 2.5 & 0.4 & 1 & 0.7 & -4.4 \\
\hline 8 & 0.4 & 2 & -2.8 & 1.6 & -1 \\
\hline
\end{tabular}




\begin{tabular}{c|c}
\hline \multicolumn{2}{c}{ Table 3: Total Connectedness Index } \\
\hline Component & Value \\
\hline 1 & 6.4 \\
2 & 7.3 \\
3 & 20.1 \\
4 & 29.2 \\
5 & 26.3 \\
6 & 29.9 \\
7 & 39.1 \\
8 & 50.5 \\
\hline \hline
\end{tabular}


Total Connectedness Index

250-RW-VAR

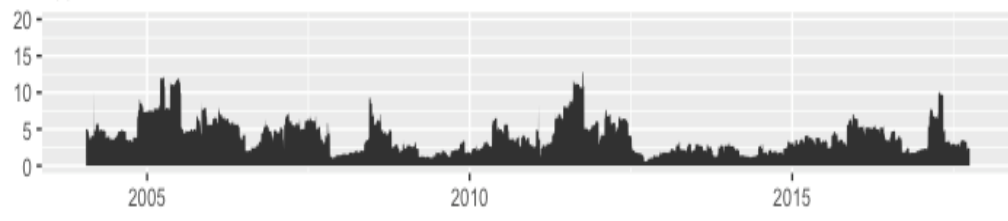

Total Connectedness Index

Level 1

$\underbrace{}_{2005}$

Total Connectedness Index

Level 3

$\underbrace{2000}_{2005}$

2005

Total Connectedness Index

Level 5

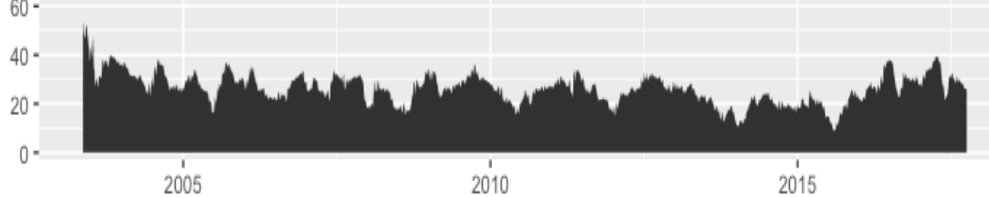

Total Connectedness Index

Level7

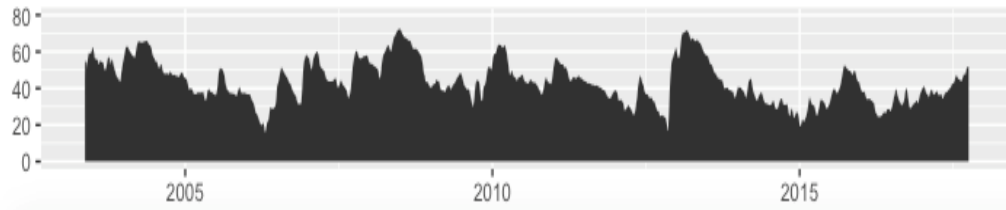

Total Connectedness Index

TVP-VAR

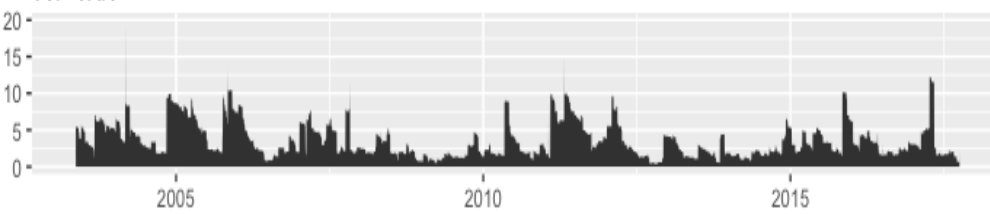

Total Connectedness Index

Level 2

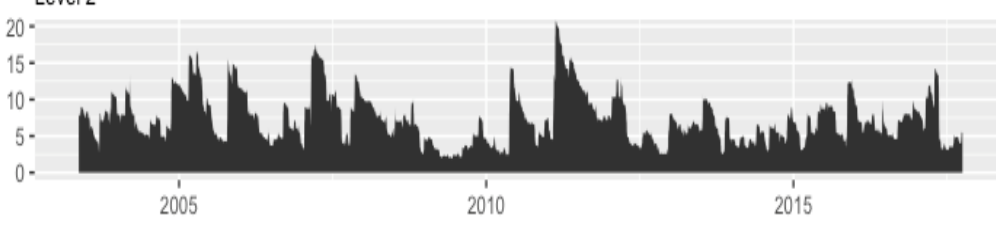

Total Connectedness Index

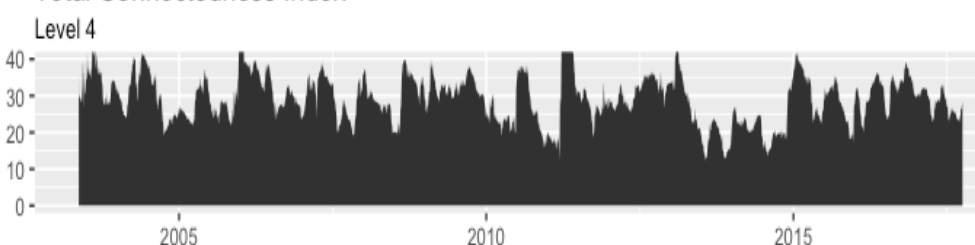

Total Connectedness Index Level 6

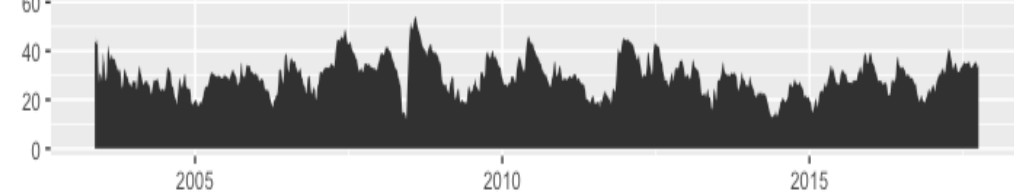

Total Connectedness Index

Level 8

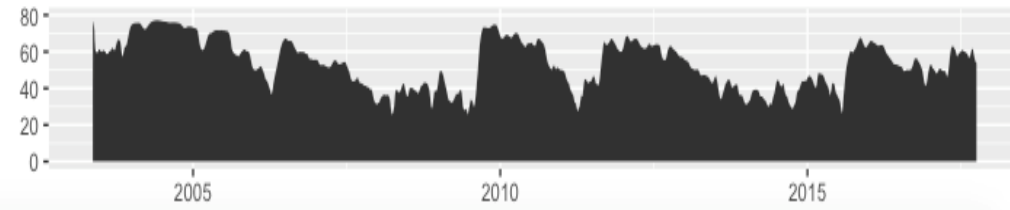

Figure 1: Total Connectedness Index of the TVP-VAR model. 
FROM US

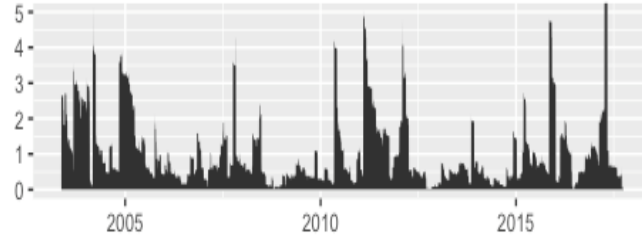

FROM EU

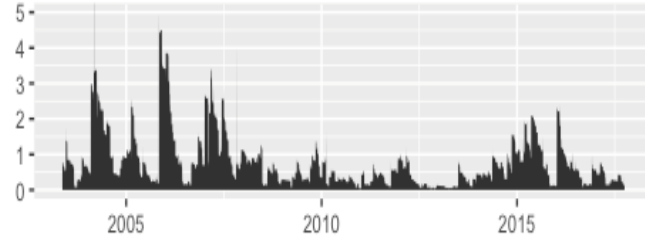

FROM UK

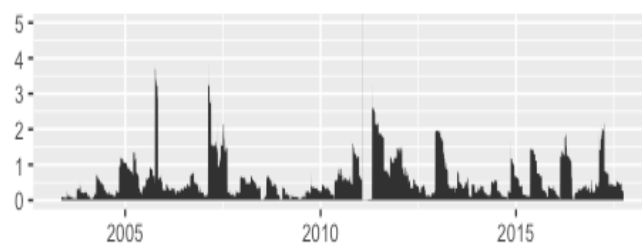

FROM CA

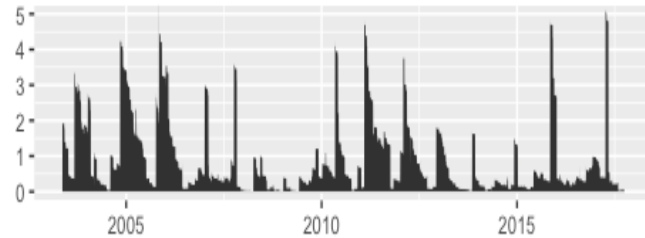

FROM JP

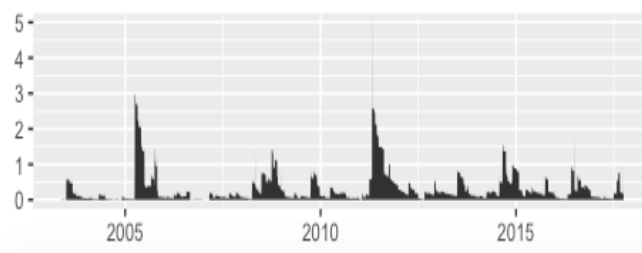

TOUS

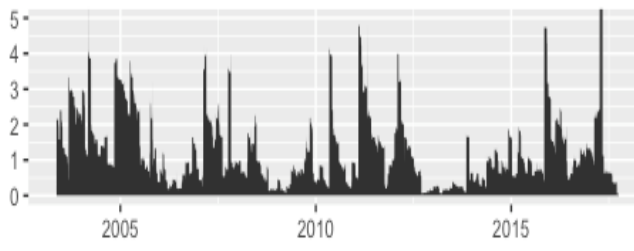

TO EU

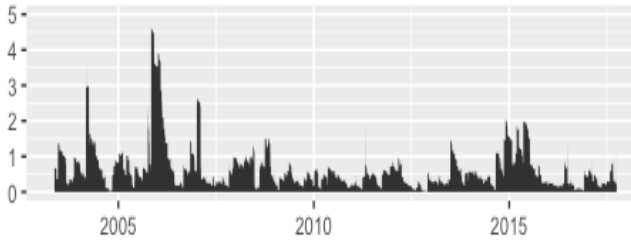

TO UK

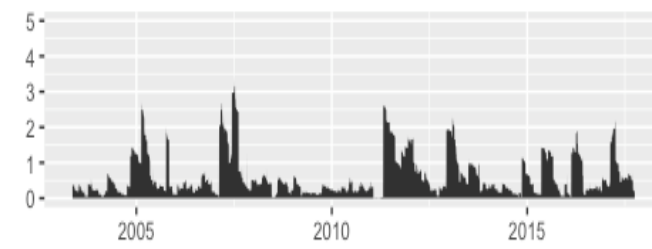

TO CA

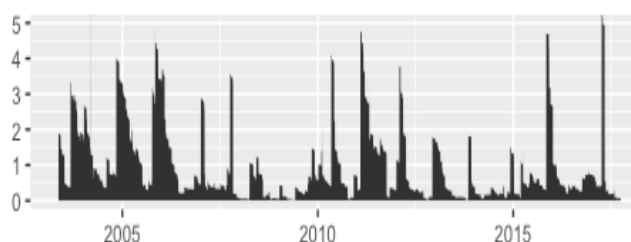

TO JP

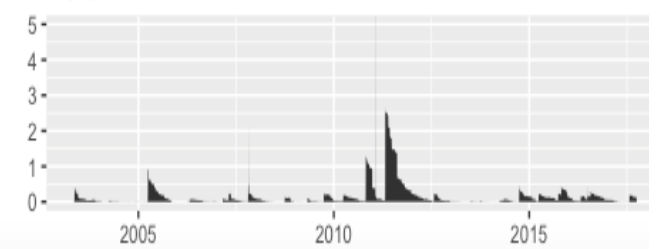

NET US

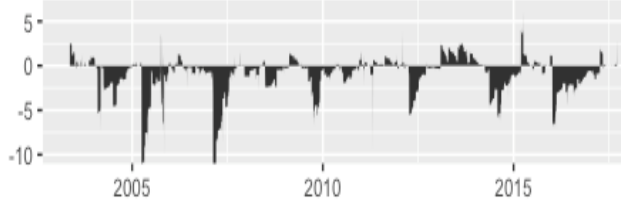

10.-

NET UK

-10.

NET CA
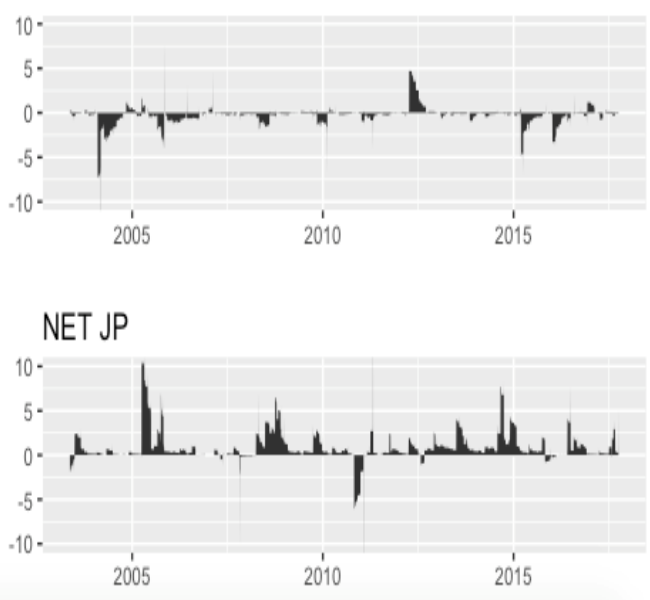

Figure 2: Net Total Directional Connectedness per country of first-differenced data. 

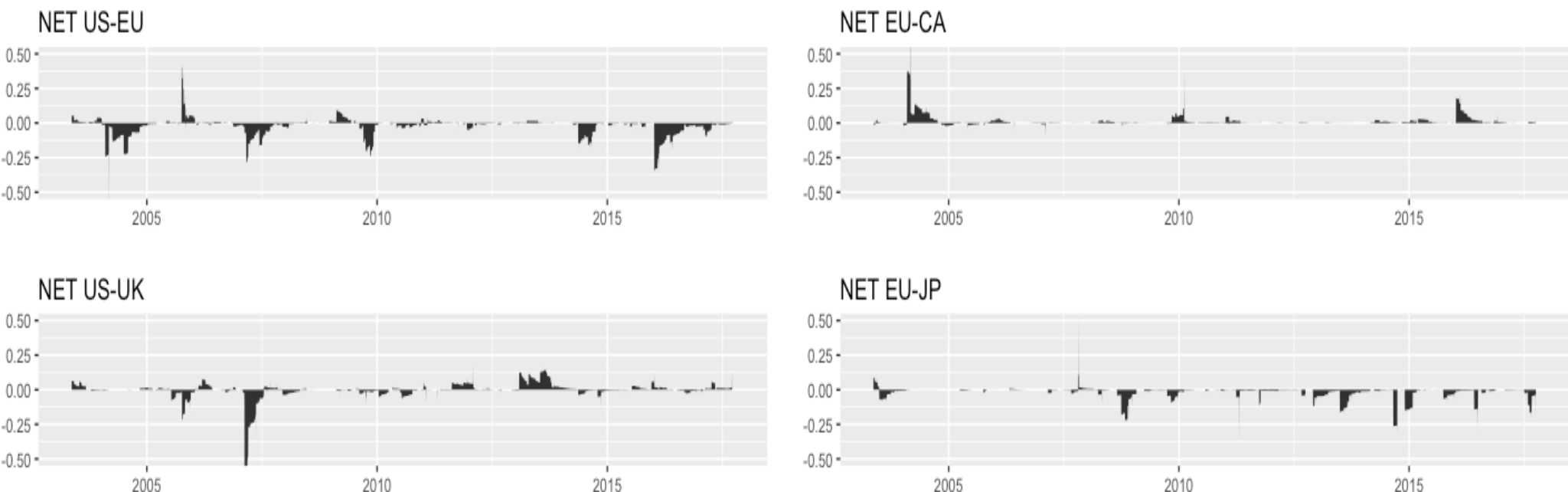

NET EU-JP
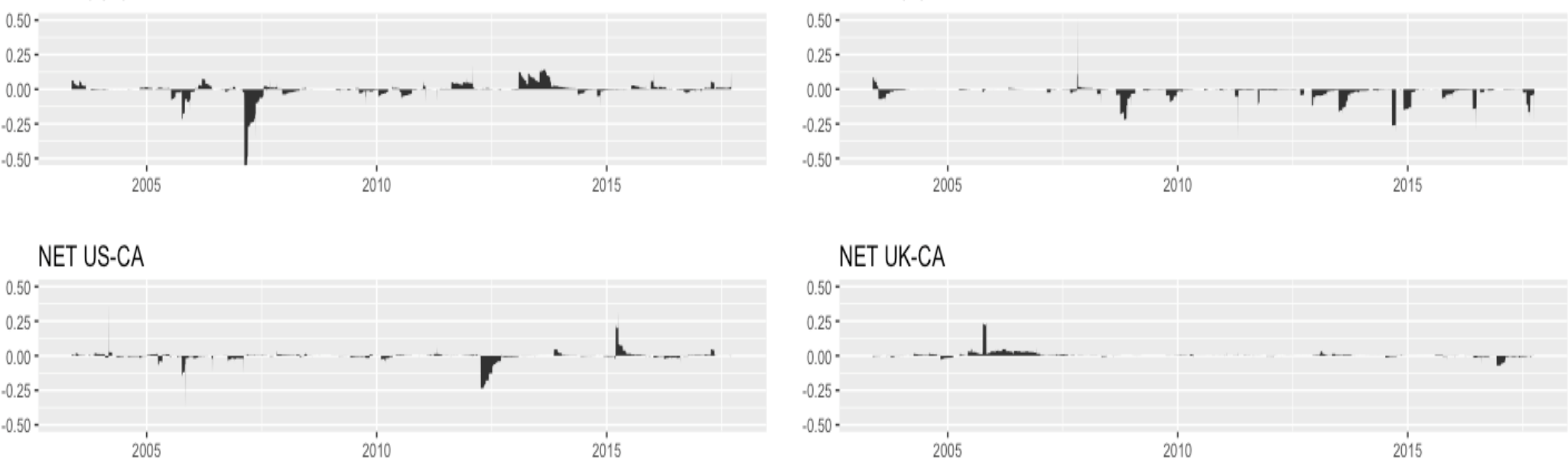

NET US-JP

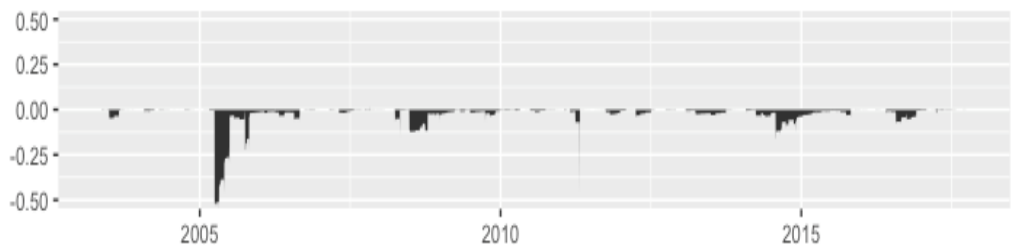

\section{NET UK-JP}
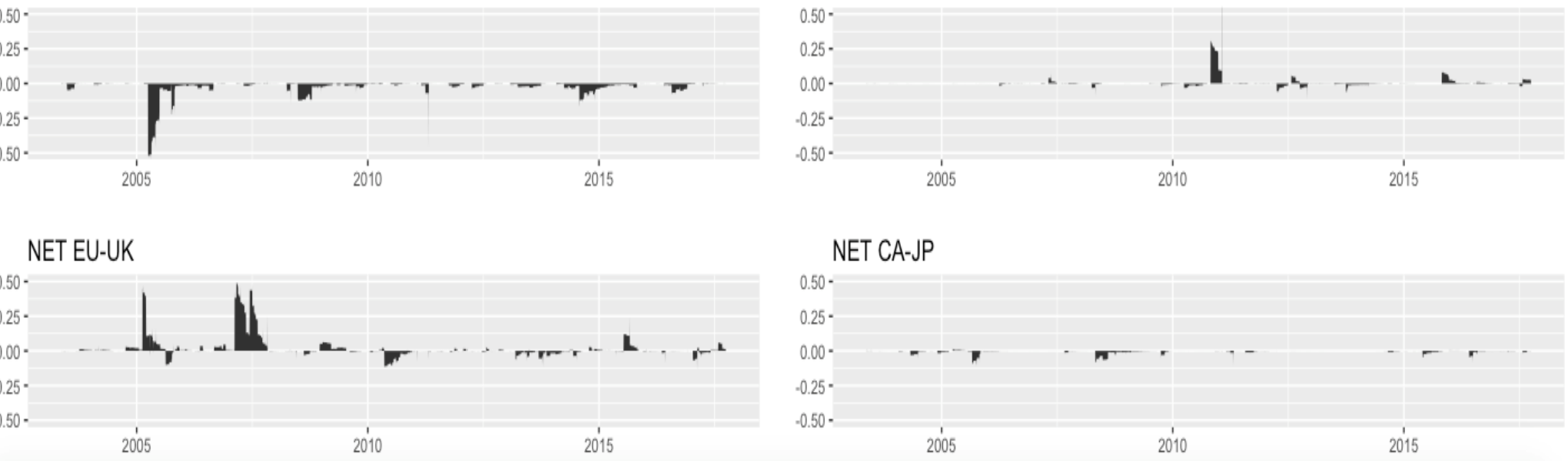

Figure 3: Net Pairwise Directional Connectedness of first-differenced data. 

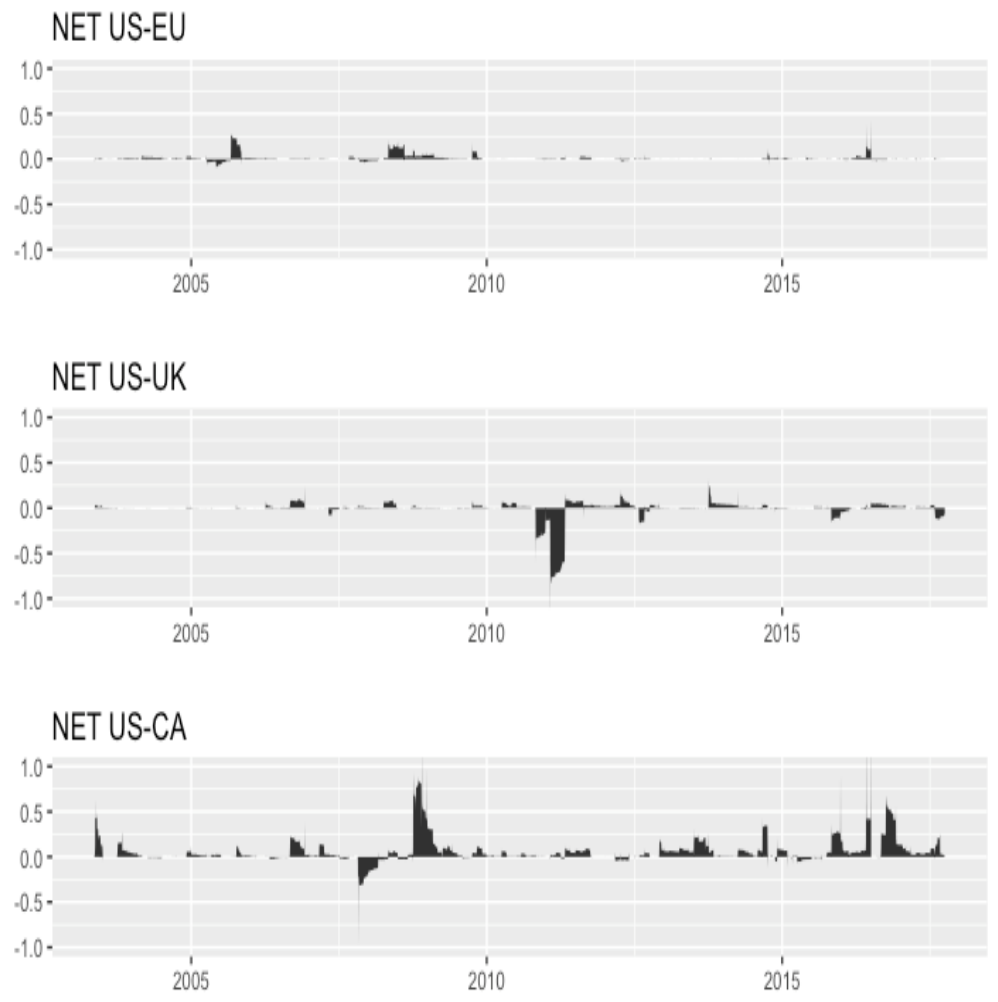

NET US-JP

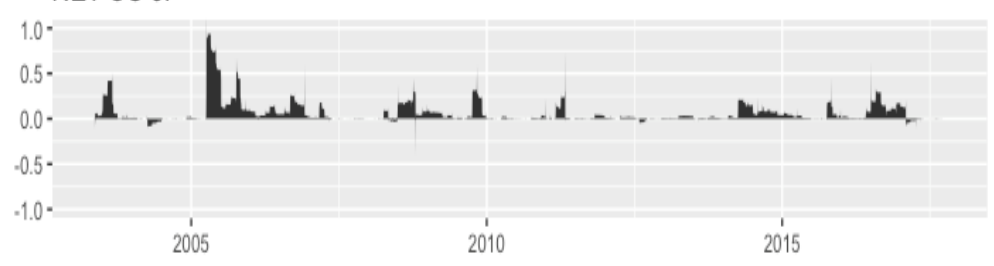

NET EU-UK

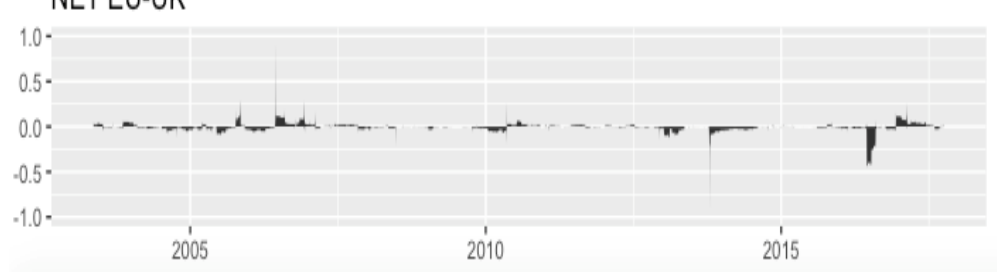

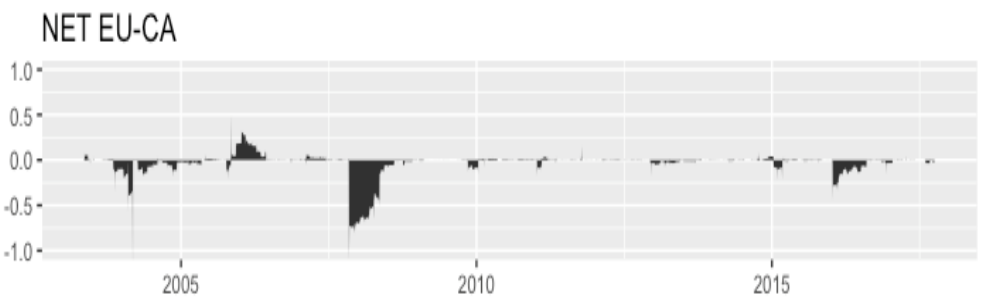

NET EU-JP
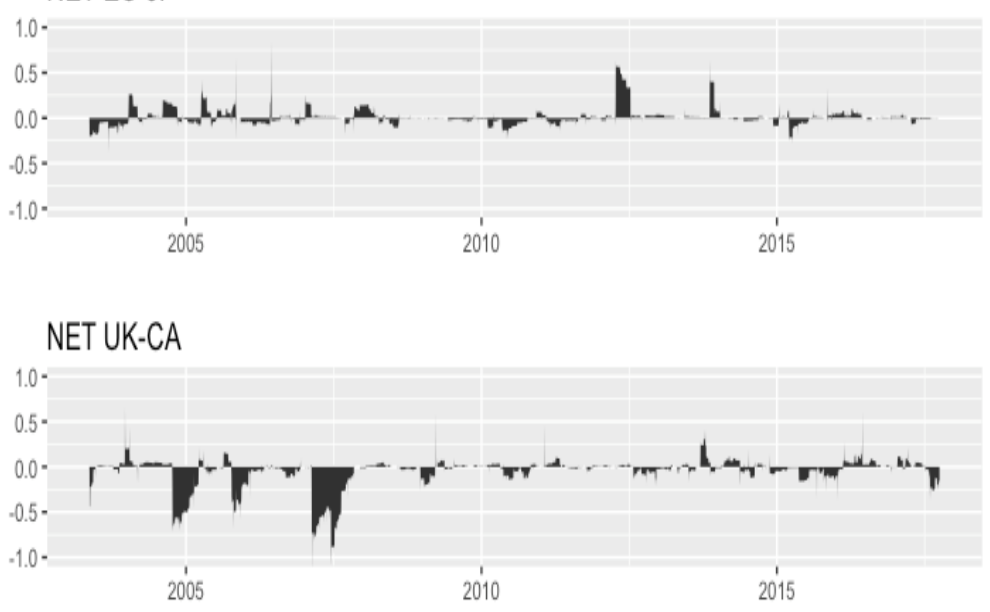

NET UK-JP

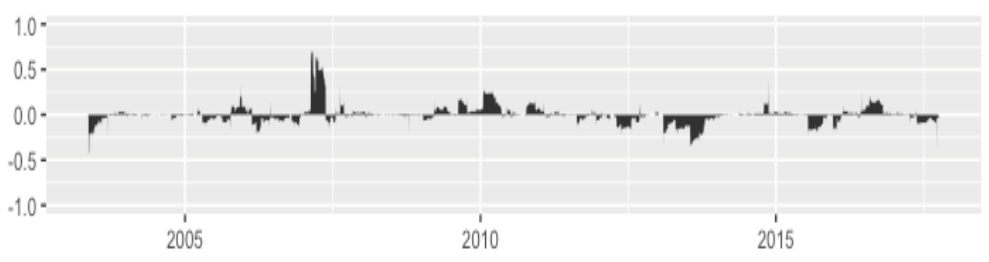

NET CA-JP

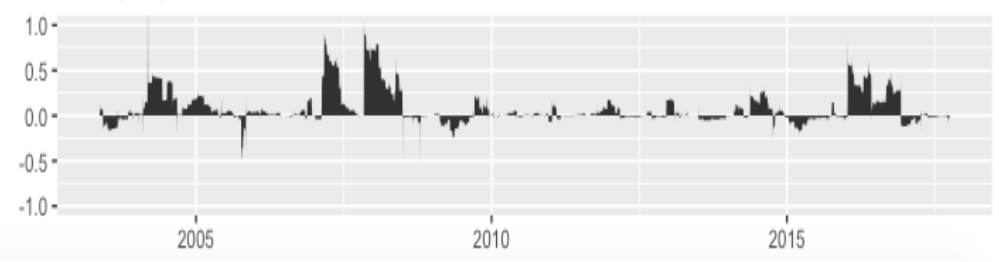

Figure 4: Net Pairwise Directional Connectedness for the $1^{\text {st }}$ Frequency Decomposition 

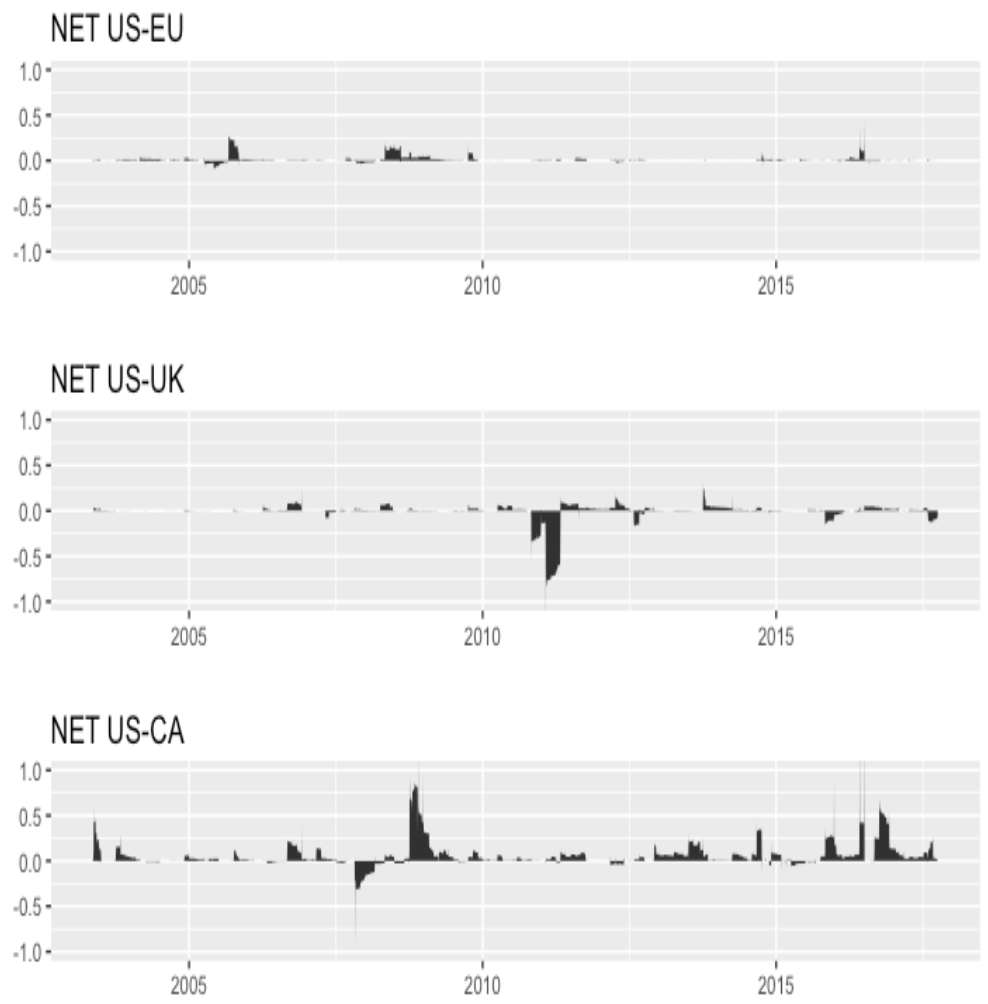

NET US-JP
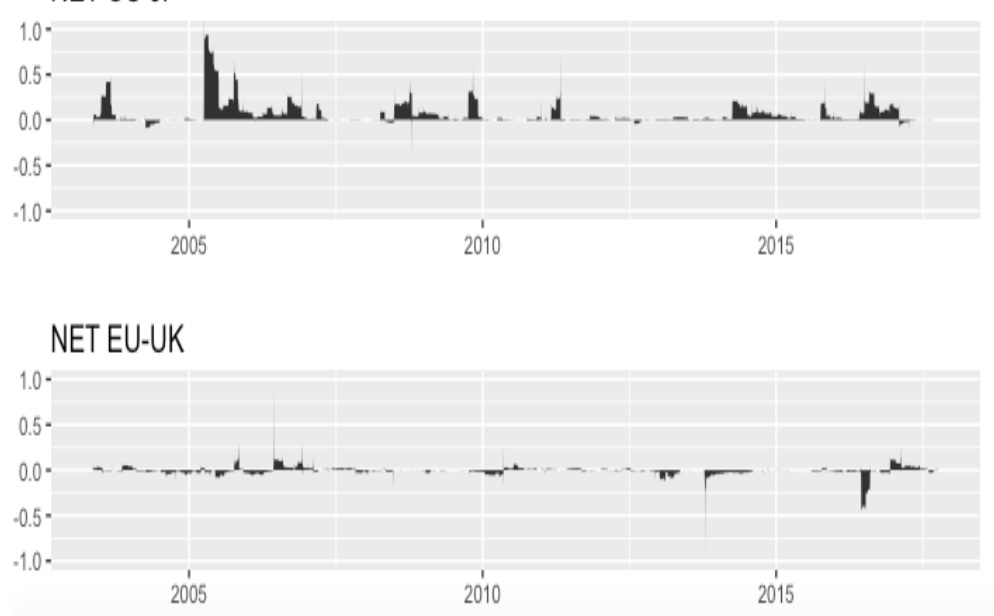

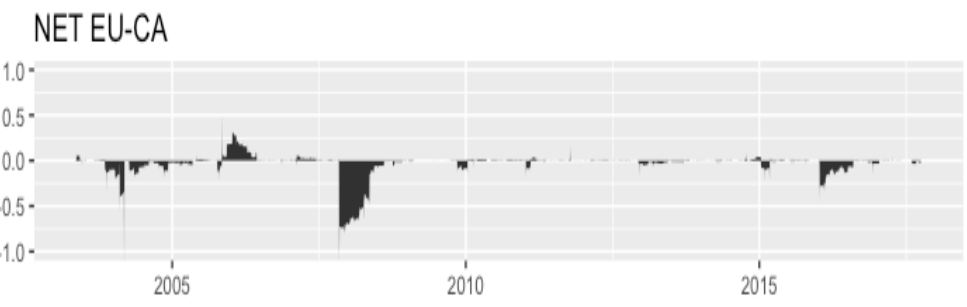

NET EU-JP
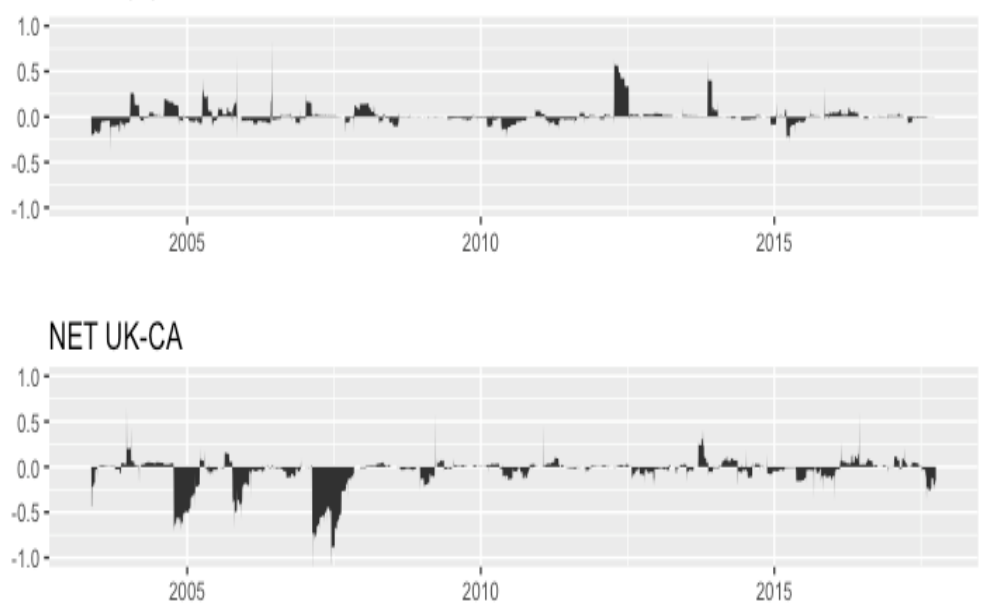

NET UK-JP
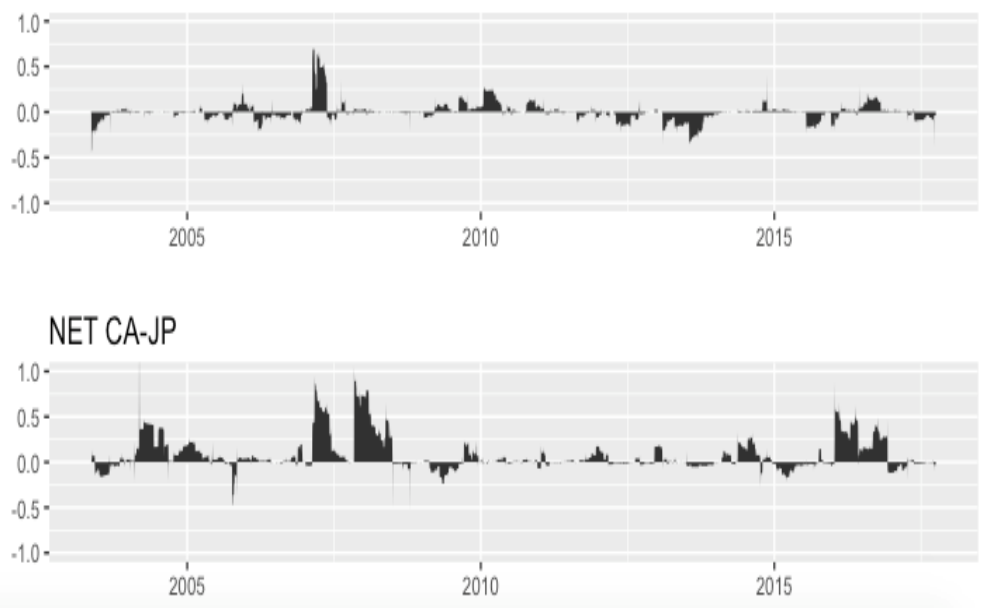

Figure 5: Net Pairwise Directional Connectedness for the $2^{\text {nd }}$ Frequency Decomposition 
NET US-EU

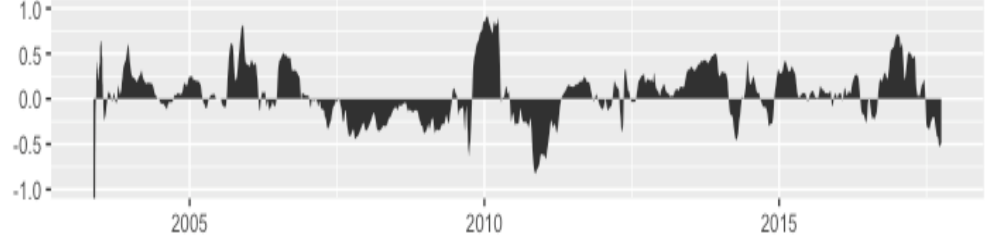

NET US-UK
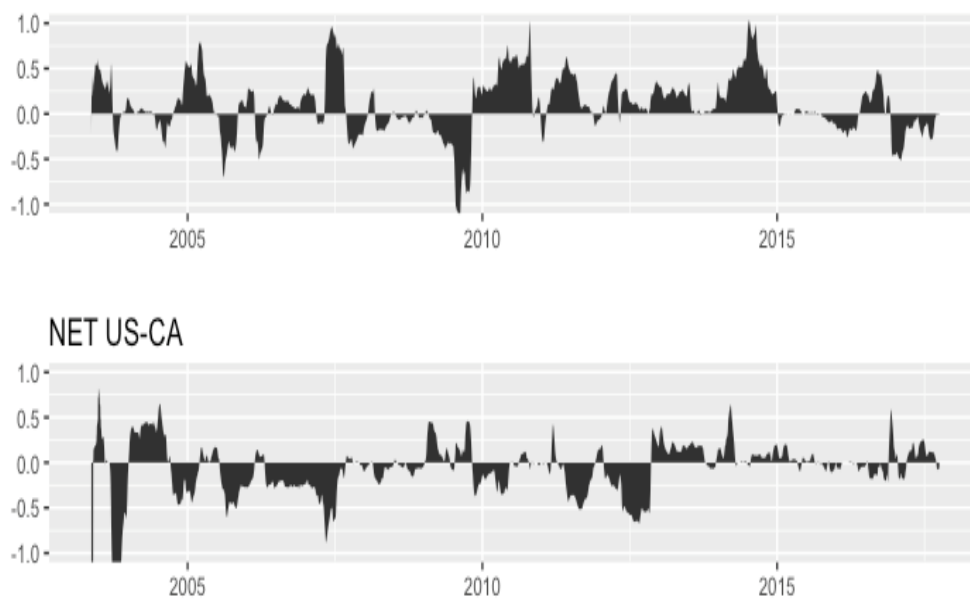

NET US-JP
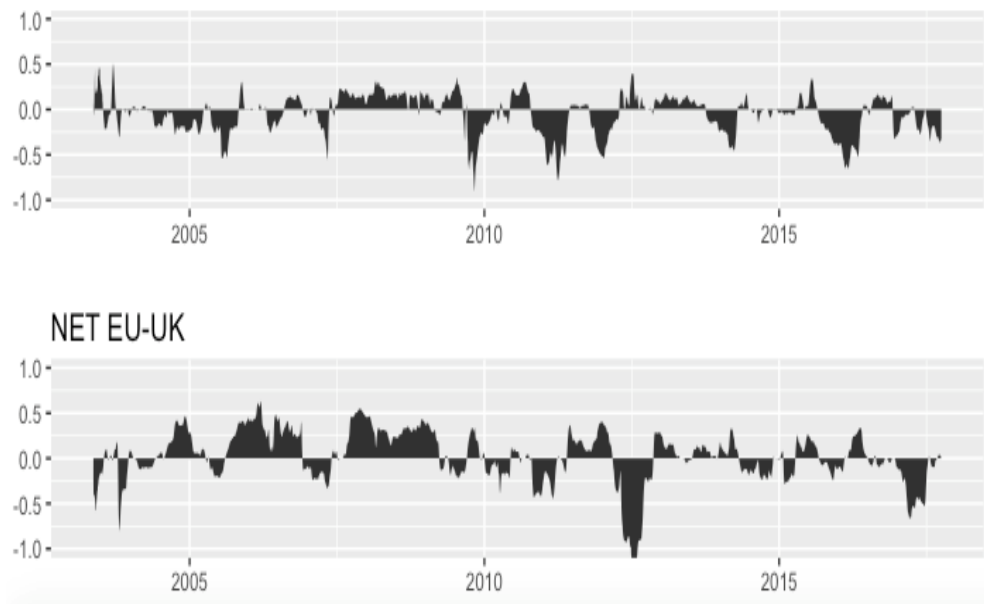

NET EU-CA

$$
\underbrace{}_{2005}
$$

NET EU-JP

$$
\|\left._{2005}\right|_{2010} ^{m}
$$

NET UK-CA

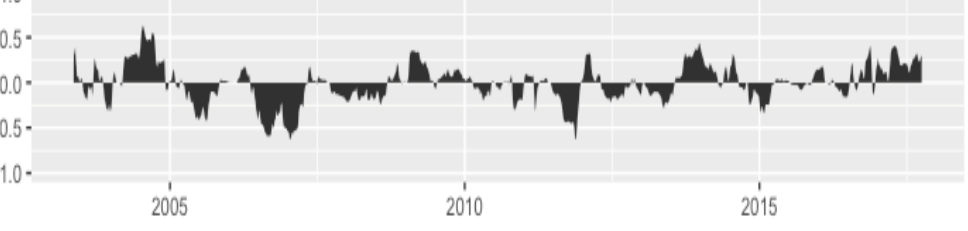

NET UK-JP

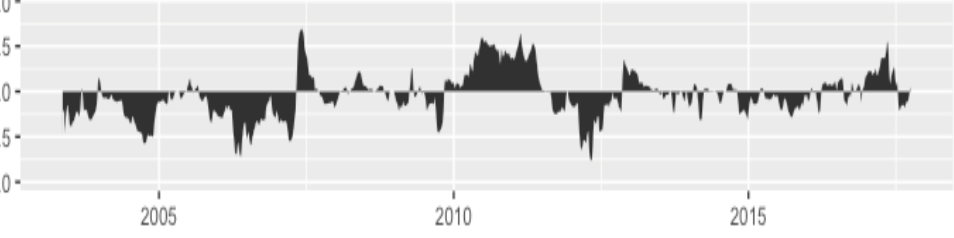

NET CA-JP

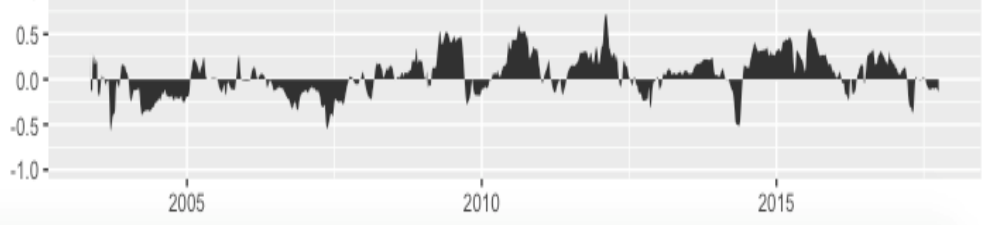

Figure 6: Net Pairwise Directional Connectedness for the $7^{\text {th }}$ Frequency Decomposition 
NET US-EU

20050

NET US-UK

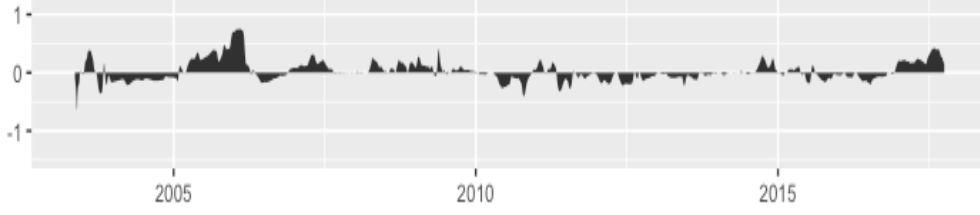

NET US-CA

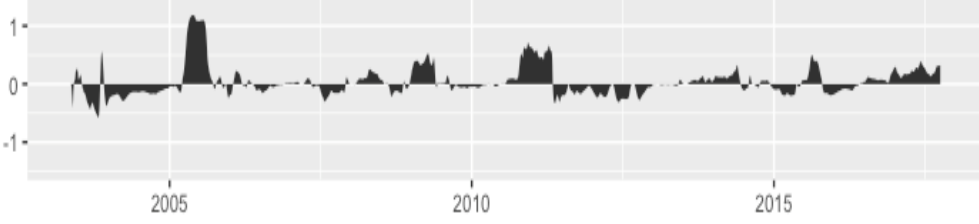

NET US-JP

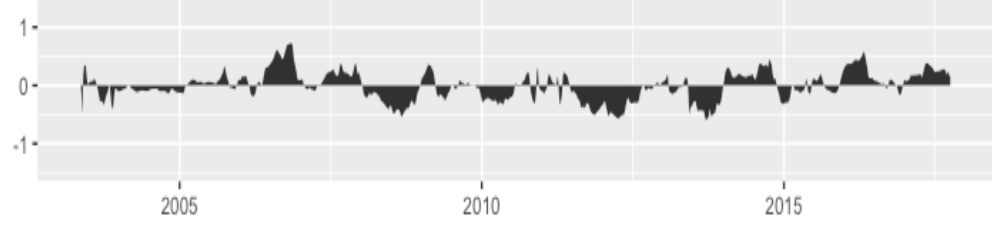

NET EU-UK

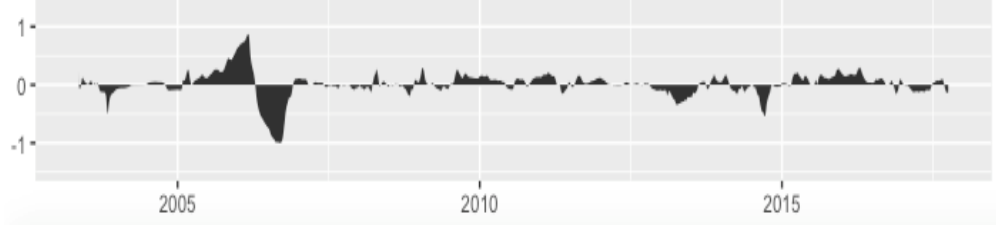

NET EU-CA

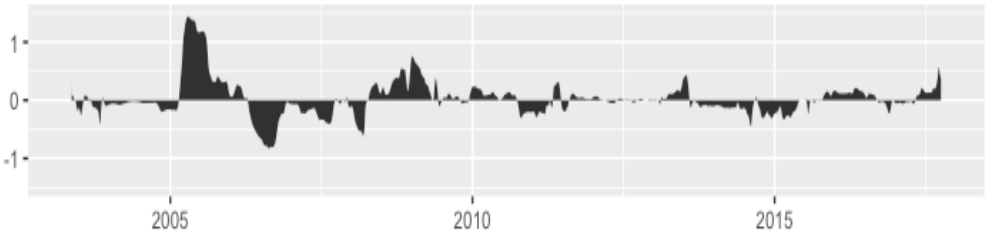

NET EU-JP

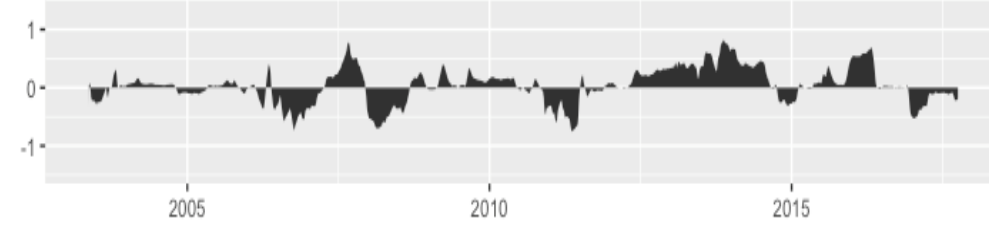

NET UK-CA

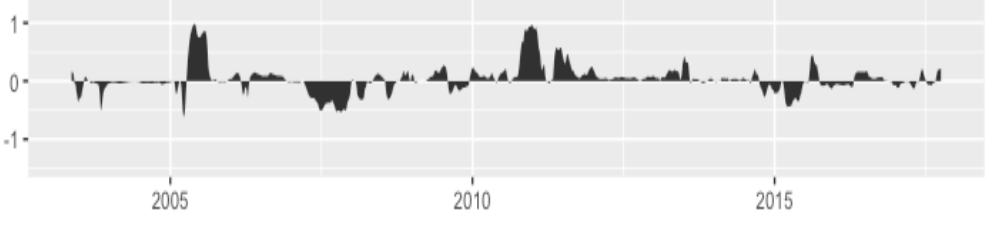

NET UK-JP

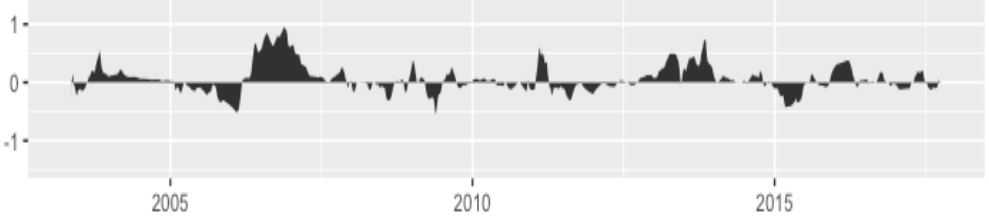

NET CA-JP

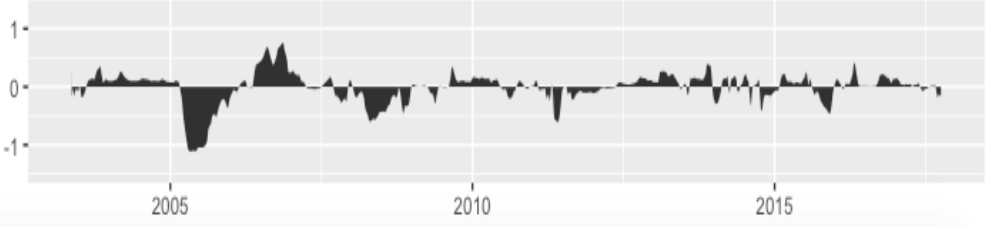

Figure 7: Net Pairwise Directional Connectedness for the $8^{\text {th }}$ Frequency Decomposition 


\section{Appendix}

\section{A. Descriptive statistics}

The daily macroeconomic uncertainty indices are from Scotti (2016) for the U.S., the U.K. Japan, Canada and the E.U. In figures A-1 we depict the uncertainty indices. As we observe that, in certain indices exist periods of constant values, we use first difference transformation (instead of first difference of logarithms) of the series to ensure stationarity and to remove periods of constant variability.

\section{A. Wavelets}

We use the maximal overlap discrete wavelet transform in order to decompose all series into their respectful component series. In Figures A-1 we depict all the decomposed series. As we observe, a large clustering in volatility occurs around the 2008 crisis for the U.S., the E.U. and the U.K. while no distinct patterns exist for Japan and Canada. Bearing in mind that the wavelet decomposition performs a decomposition in the frequency and not in the time domain, the order of the components reveals different characteristics over time. Thus, the first components adhere to fluctuation in the short-run, while the last components reveal variations in the longest horizon. 


\section{Uncertainty Index}

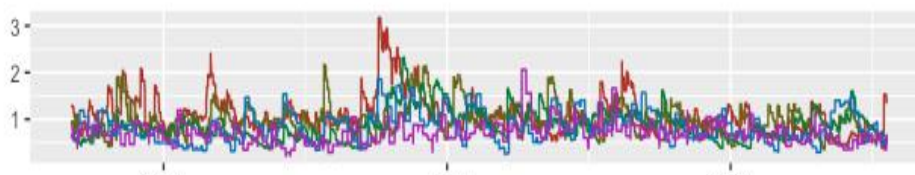

2005

2010

2015

Uncertainty Index

Level 1

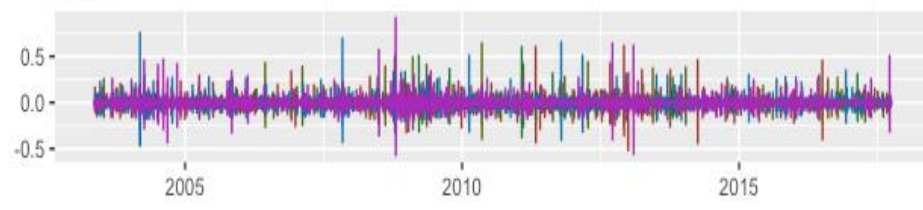

2005

2010

2015

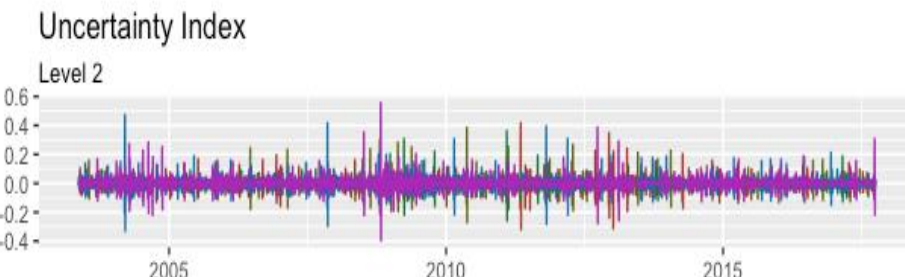

2005

2010

2015
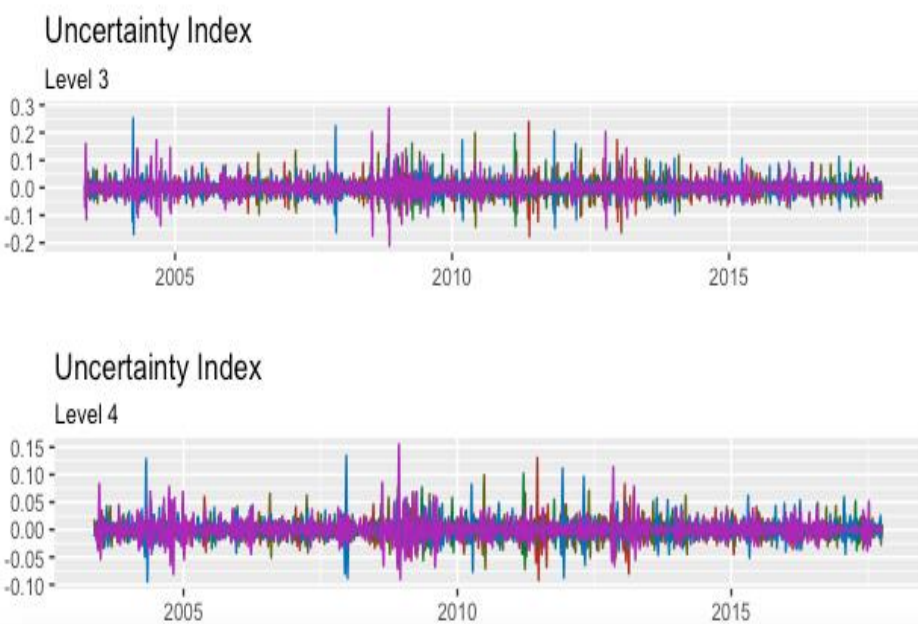

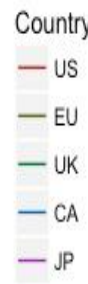

Country

- us

- EU

$-U K$

$-C A$

$-\mathrm{JP}$

Country

- Us

- EU

$-u k$

$-C A$

$-\mathrm{sP}$

Country

- Us

- EU

$-U K$

$-C A$

$-\mathrm{sp}$

Country
$-U S$
$-E U$
$-U K$
$-C A$
$-J P$
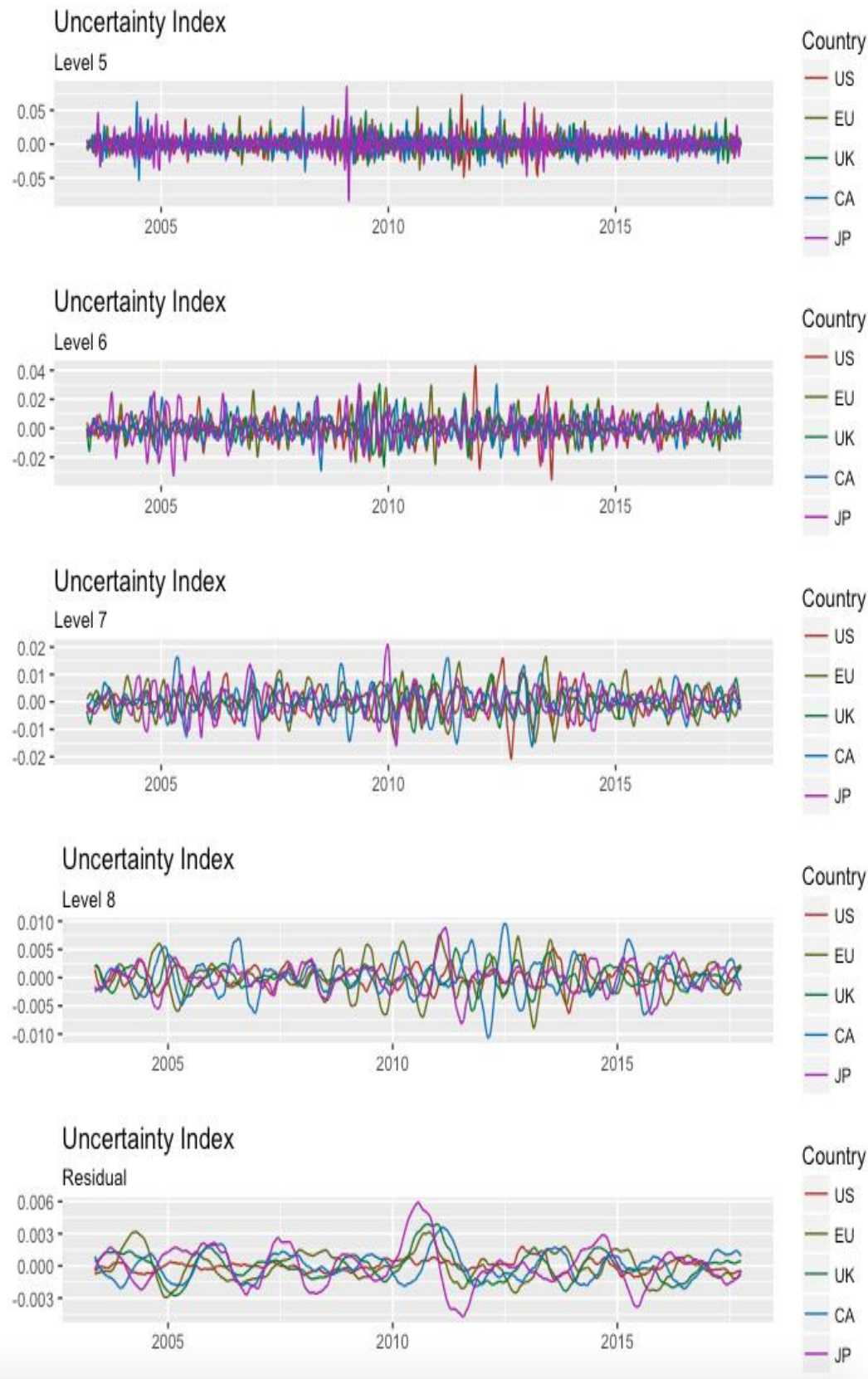

Figure A-1: Daily Uncertainty Indices and Decomposition of the daily indices in first-differences 


\section{Dynamic Connectedness results based on a VAR model}

For comparison reasons of our TVP-VAR(1) model with the work of Diebold and Yilmaz (2012), we also employ a 250-day rolling window VAR(1) model with constant parameters in order to measure the differences between the two approaches. In Table A-1 we report the uncertainty connectedness of the VAR model.

\begin{tabular}{c|r|r|r|r|r|r}
\hline \hline & \multicolumn{7}{c}{ Table A-1: Uncertainty spillover connectedness for VAR model } \\
\hline & U.S. & \multicolumn{1}{|c}{ E.U. } & \multicolumn{1}{c}{ U.K. } & \multicolumn{1}{c}{ Canada } & Japan & FROM \\
\hline U.S. & 92.7 & 1.9 & 0.9 & 3.4 & 1.2 & 7.3 \\
E.U. & 1.1 & 96.6 & 1 & 0.8 & 0.5 & 3.4 \\
U.K. & 0.9 & 1.9 & 96.3 & 0.5 & 0.4 & 3.7 \\
Canada & 3.3 & 1.2 & 0.9 & 94.5 & 0.1 & 5.5 \\
Japan & 0.1 & 0.1 & 0.4 & 0.1 & 99.4 & 0.6 \\
\hline Contribution & & & & & & \\
TO others & 5.3 & 5.1 & 3.2 & 4.8 & 2.2 & 20.5 \\
\hline Contribution & & & & & & \\
including & & & & & & \\
own & 98 & 101.7 & 99.5 & 99.3 & 101.6 & \\
\hline Net & & & & & & \\
spillovers & -2 & 1.7 & -0.5 & -0.7 & 1.6 & $\mathbf{4 . 1}$ \\
\hline \hline
\end{tabular}

Note: All values are percentages. The number in bold (bottom right corner) represents the total connectedness of the system. Its ijth entry is the estimated contribution to the forecast error variance of economy $i$ coming from innovations to economy $j$. The diagonal elements reveal self-inflicting uncertainty, while all the off-diagonal elements report spillover rates.

As we observe, the reported connectedness indices are similar to the ones reported for the TVP-VAR model in Table 1 of the main body of the paper. The net spillovers for the U.S., the E.U., Canada and Japan are twice in absolute numbers for the VAR mode than those reported by the TVP-VAR model, and five times greater for the U.K. The signs remain the same indicating the same transmission direction. Nevertheless, the percentages remain very small between $0.5 \%$ and $2 \%$ in absolute numbers. The total net spillovers of the entire network are slightly larger for the VAR model from 3.6\% to 4.1\%, but the change is not important. Thus, the use of the VAR or the TVP-VAR reaches to similar results. In figures A-11 and A-12 we depict the net volatility spillovers per country and the net pairwise volatility spillovers. Once again the examination per time period gives similar results to the ones of the TVP-VAR model. 

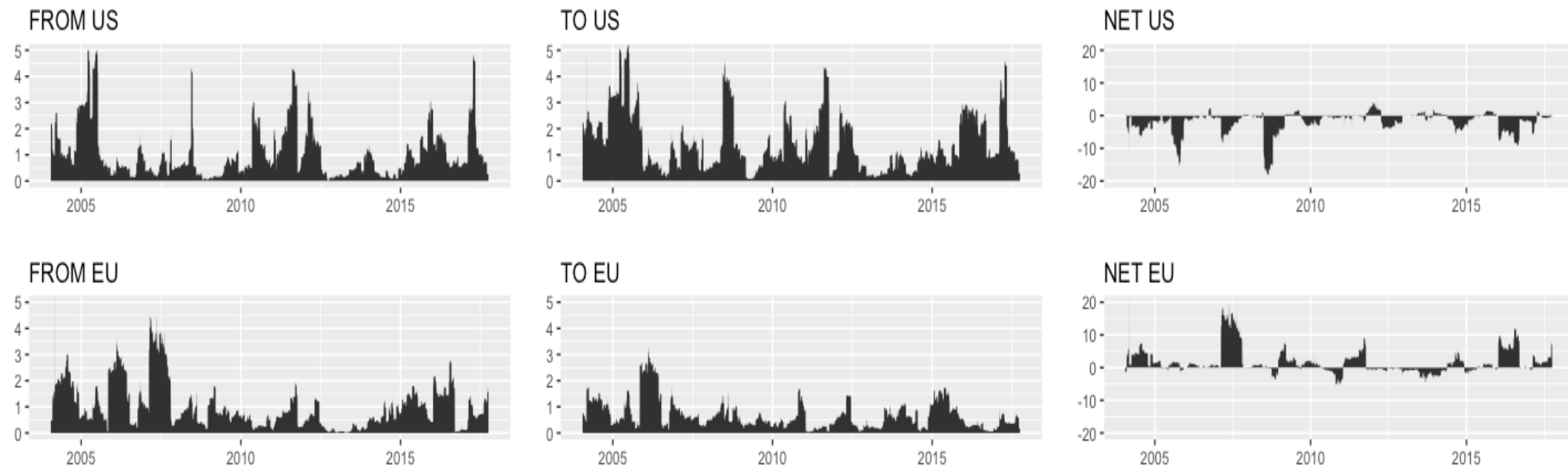

NET EU
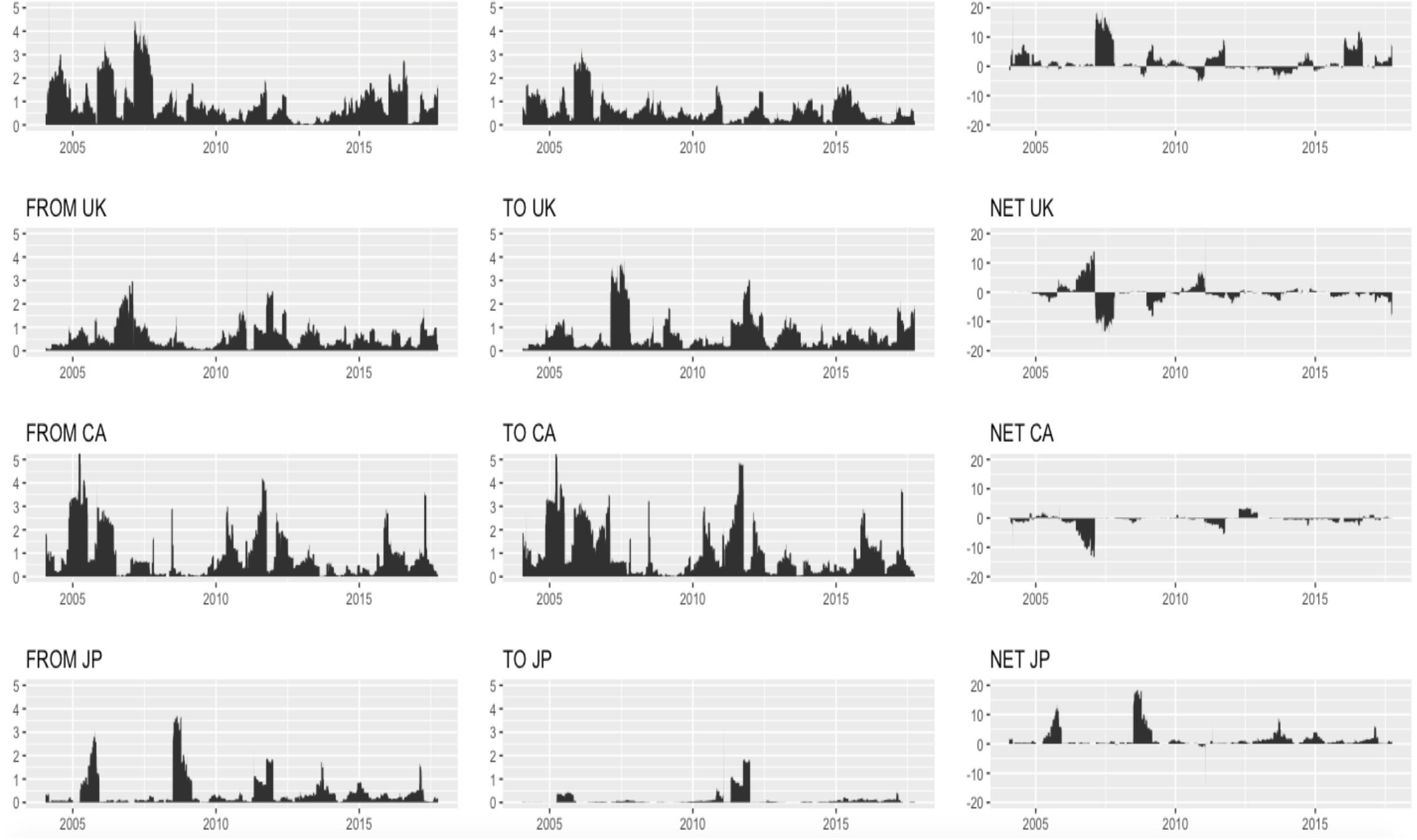

NET JP

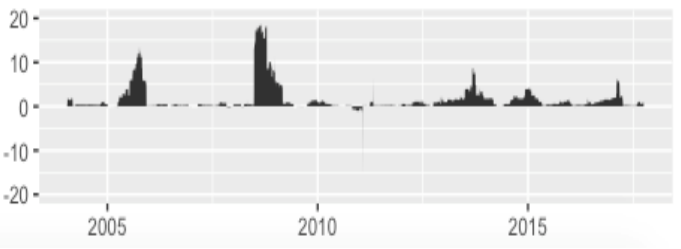

Figure A-11: Net Volatility Spillovers per country for the VAR model. 

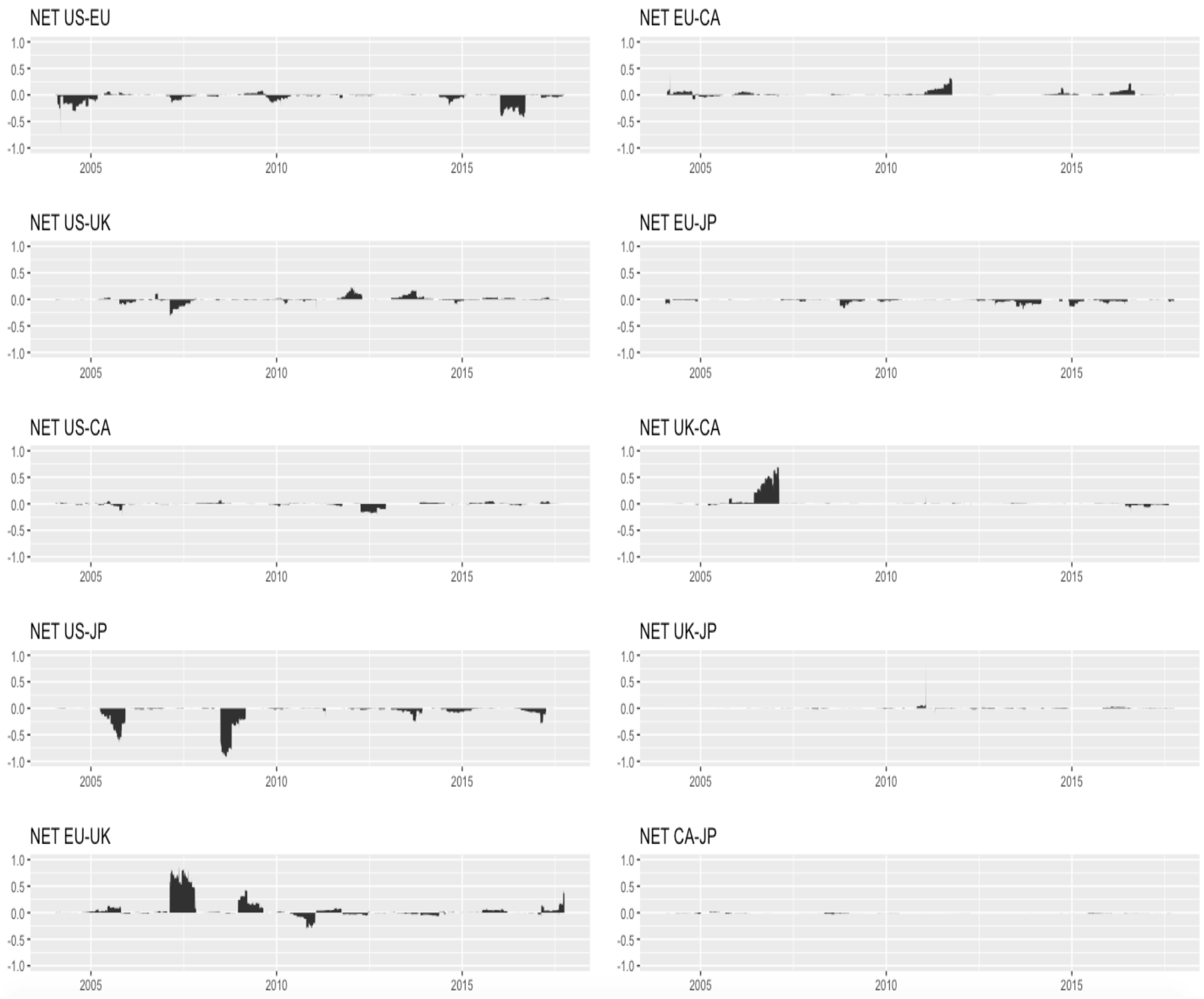

Figure A-12: Net Pairwise Volatility Spillover of the VAR model. 


\section{Dynamic Connectedness results for the wavelet components}

\begin{tabular}{|c|c|c|c|c|c|c|}
\hline \multicolumn{7}{|c|}{ Table A-1: Uncertainty spillover connectedness for the $1^{\text {st }}$ component } \\
\hline & U.S. & E.U. & U.K. & Canada & Japan & FROM \\
\hline U.S. & 97.6 & 0.2 & 0.8 & 0.8 & 0.6 & 2.4 \\
\hline E.U. & 0.4 & 93.3 & 1.0 & 1.7 & 3.6 & 6.7 \\
\hline U.K. & 0.7 & 0.9 & 94.1 & 2.7 & 1.7 & 5.9 \\
\hline Canada & 1.9 & 1.0 & 1.6 & 93.6 & 1.9 & 6.4 \\
\hline Japan & 1.8 & 3.7 & 1.6 & 3.5 & 89.4 & 10.6 \\
\hline $\begin{array}{c}\text { Contribution } \\
\text { TO others }\end{array}$ & 4.7 & 5.8 & 5.1 & 8.6 & 7.7 & 32.0 \\
\hline $\begin{array}{l}\text { Contribution } \\
\text { including own }\end{array}$ & 102.3 & 99.1 & 99.2 & 102.2 & 97.1 & \\
\hline Net spillovers & 2.3 & -0.9 & -0.8 & 2.2 & -2.9 & 6.4 \\
\hline
\end{tabular}

Note: All values are percentages. The number in bold (bottom right corner) represents the total connectedness of the system. Its ijth entry is the estimated contribution to the forecast error variance of economy $i$ coming from innovations to economy $j$. The diagonal elements reveal self-inflicting uncertainty, while all the off-diagonal elements report spillover rates.

\begin{tabular}{|c|c|c|c|c|c|c|}
\hline & & \multicolumn{5}{|c|}{ Table A-2: Uncertainty spillover connectedness for the $2^{\text {nd }}$ component } \\
\hline & U.S. & E.U. & U.K. & Canada & Japan & FROM \\
\hline U.S. & 96 & 0.3 & 1.3 & 1.5 & 0.9 & 4 \\
\hline E.U. & 0.5 & 92.1 & 1.2 & 2.3 & 3.8 & 7.9 \\
\hline U.K. & 1.3 & 1.2 & 93.1 & 2.2 & 2.1 & 6.9 \\
\hline Canada & 1.7 & 2.1 & 2.1 & 91.9 & 2.1 & 8.1 \\
\hline Japan & 1.7 & 3.5 & 1.9 & 2.6 & 90.2 & 9.8 \\
\hline $\begin{array}{c}\text { Contribution } \\
\text { TO others }\end{array}$ & 5.3 & 7.1 & 6.5 & 8.6 & 9 & 36.5 \\
\hline $\begin{array}{l}\text { Contribution } \\
\text { including own }\end{array}$ & 101.3 & 99.3 & 99.6 & 100.5 & 99.3 & \\
\hline Net spillovers & 1.3 & -0.7 & -0.4 & 0.5 & -0.7 & 7.3 \\
\hline
\end{tabular}

Note: All values are percentages. The number in bold (bottom right corner) represents the total connectedness of the system. Its ijth entry is the estimated contribution to the forecast error variance of economy $i$ coming from innovations to economy $j$. The diagonal elements reveal self-inflicting uncertainty, while all the off-diagonal elements report spillover rates.

\begin{tabular}{c|c|c|c|c|c|c}
\hline \hline \multicolumn{7}{c}{ Table A-3: Uncertainty spillover connectedness for the $3^{\text {rd }}$ component } \\
\hline & U.S. & E.U. & U.K. & Canada & Japan & FROM \\
\hline U.S. & 84.6 & 3.6 & 4 & 3.7 & 4.1 & 15.4 \\
E.U. & 3.8 & 78.9 & 4.8 & 6.9 & 5.7 & 21.1 \\
U.K. & 3.6 & 4.8 & 81.7 & 6.3 & 3.5 & 18.3 \\
Canada & 6.1 & 6.5 & 5.3 & 76.7 & 5.4 & 23.3 \\
Japan & 4.9 & 7.4 & 4.4 & 5.7 & 77.6 & 22.4 \\
\hline Contribution & 18.3 & 22.3 & 18.6 & 22.6 & 18.7 & 100.5 \\
TO others & 102.9 & 101.2 & 100.3 & 99.4 & 96.2 & \\
\hline Contribution & 10.2 & 0.3 & -0.6 & -3.8 & $\mathbf{2 0 . 1}$ \\
including own & 1.2 & & & \\
\hline Net spillovers & 2.9 & 1.2 &
\end{tabular}

Note: All values are percentages. The number in bold (bottom right corner) represents the total connectedness of the system. Its ijth entry is the estimated contribution to the forecast error variance 
of economy $i$ coming from innovations to economy $j$. The diagonal elements reveal self-inflicting uncertainty, while all the off-diagonal elements report spillover rates.

\begin{tabular}{c|c|c|c|c|c|c}
\hline \multicolumn{7}{c}{ Table A-4: Uncertainty spillover connectedness for the $4^{\text {th }}$ component } \\
\hline & U.S. & E.U. & U.K. & Canada & Japan & FROM \\
\hline U.S. & 72.7 & 6.5 & 8.3 & 5.5 & 7.1 & 27.3 \\
E.U. & 6.2 & 71.8 & 6.2 & 7.5 & 8.3 & 28.2 \\
U.K. & 5.2 & 8.3 & 71.7 & 6.4 & 8.4 & 28.3 \\
Canada & 7.7 & 10.1 & 6.7 & 69.2 & 6.4 & 30.8 \\
Japan & 8 & 8.3 & 6 & 9.1 & 68.6 & 31.4 \\
\hline Contribution & 27 & 33.2 & 27.2 & 28.5 & 30.2 & 146.1 \\
TO others & & 105 & 98.9 & 97.6 & 98.8 & \\
\hline Contribution & 99.7 & 105 & -1.1 & -2.4 & -1.2 & $\mathbf{2 9 . 2}$ \\
including own & & 5 & &
\end{tabular}

Note: All values are percentages. The number in bold (bottom right corner) represents the total connectedness of the system. Its ijth entry is the estimated contribution to the forecast error variance of economy $i$ coming from innovations to economy $j$. The diagonal elements reveal self-inflicting uncertainty, while all the off-diagonal elements report spillover rates.

\begin{tabular}{c|c|c|c|c|c|c}
\hline \hline \multicolumn{7}{c}{ Table A-5: Uncertainty spillover connectedness for the $5^{\text {th }}$ component } \\
\hline & U.S. & E.U. & U.K. & Canada & Japan & FROM \\
\hline U.S. & 74 & 8.2 & 7.6 & 5.6 & 4.7 & 26 \\
E.U. & 4.8 & 72.4 & 8.8 & 8.5 & 5.5 & 27.6 \\
U.K. & 4.5 & 8 & 73.2 & 7.5 & 6.8 & 26.8 \\
Canada & 6.6 & 7.3 & 4.8 & 73.8 & 7.5 & 26.2 \\
Japan & 6.6 & 4.6 & 5.8 & 7.8 & 75.1 & 24.9 \\
\hline Contribution & 22.6 & 28.1 & 27 & 29.4 & 24.5 & 131.5 \\
TO others & 22.6 & 100.2 & 103.2 & 99.6 & \\
\hline Contribution & 96.5 & 100.5 & 0.5 & 3.2 & -0.4 & $\mathbf{2 6 . 3}$ \\
including own & & & & & & \\
\hline Net spillovers & -3.5 & 0.5 & 0.2 & &
\end{tabular}

Note: All values are percentages. The number in bold (bottom right corner) represents the total connectedness of the system. Its $i j t h$ entry is the estimated contribution to the forecast error variance of economy $i$ coming from innovations to economy $j$. The diagonal elements reveal self-inflicting uncertainty, while all the off-diagonal elements report spillover rates.

\begin{tabular}{|c|c|c|c|c|c|c|}
\hline \multicolumn{7}{|c|}{ Table A-6: Uncertainty spillover connectedness for the $6^{\text {th }}$ component } \\
\hline & U.S. & E.U. & U.K. & Canada & Japan & FROM \\
\hline U.S. & 71.8 & 5.6 & 7.3 & 7.6 & 7.6 & 28.2 \\
\hline E.U. & 7.3 & 69.7 & 7.6 & 7.8 & 7.6 & 30.3 \\
\hline U.K. & 5.9 & 6.9 & 73.5 & 4.9 & 8.8 & 26.5 \\
\hline Canada & 8.7 & 8.9 & 5.2 & 68.6 & 8.6 & 31.4 \\
\hline Japan & 8.3 & 7.1 & 7.2 & 10.5 & 66.8 & 33.2 \\
\hline $\begin{array}{c}\text { Contribution } \\
\text { TO others }\end{array}$ & 30.2 & 28.4 & 27.3 & 30.9 & 32.8 & 149.6 \\
\hline $\begin{array}{l}\text { Contribution } \\
\text { including own }\end{array}$ & 102.1 & 98.2 & 100.8 & 99.4 & 99.6 & \\
\hline Net spillovers & 2.1 & -1.8 & 0.8 & -0.6 & -0.4 & 29.9 \\
\hline
\end{tabular}

Note: All values are percentages. The number in bold (bottom right corner) represents the total connectedness of the system. Its ijth entry is the estimated contribution to the forecast error variance 
of economy $i$ coming from innovations to economy $j$. The diagonal elements reveal self-inflicting uncertainty, while all the off-diagonal elements report spillover rates.

\begin{tabular}{c|c|c|c|c|c|c}
\hline \hline \multicolumn{7}{c}{ Table A-7: Uncertainty spillover connectedness for the $7^{\text {th }}$ component } \\
\hline & U.S. & E.U. & U.K. & Canada & Japan & FROM \\
\hline U.S. & 63.9 & 10.6 & 8.9 & 10.7 & 6 & 36.1 \\
E.U. & 11 & 60.3 & 9.6 & 11.8 & 7.3 & 39.7 \\
U.K. & 10.6 & 9.4 & 57.3 & 12.1 & 10.6 & 42.7 \\
Canada & 10 & 11.3 & 13.6 & 58.3 & 6.8 & 41.7 \\
Japan & 7 & 8.8 & 11.6 & 7.8 & 64.9 & 35.1 \\
\hline Contribution & 38.6 & 40.1 & 43.7 & 42.4 & 30.7 & 195.4 \\
TO others & \multirow{2}{*}{10.4} & 101.1 & 100.7 & 95.5 & \\
\hline Contribution & 102.4 & 100.3 & 1.1 & 0.7 & -4.5 & $\mathbf{3 9 . 1}$ \\
including own & & 0.3 & 1.1 & \\
\hline Net spillovers & 2.4 & &
\end{tabular}

Note: All values are percentages. The number in bold (bottom right corner) represents the total connectedness of the system. Its ijth entry is the estimated contribution to the forecast error variance of economy $i$ coming from innovations to economy $j$. The diagonal elements reveal self-inflicting uncertainty, while all the off-diagonal elements report spillover rates.

\begin{tabular}{c|c|c|c|c|c|c}
\hline \hline \multicolumn{7}{c}{ Table A-8: Uncertainty spillover connectedness for the $8^{\text {th }}$ component } \\
\hline & U.S. & E.U. & U.K. & Canada & Japan & FROM \\
\hline U.S. & 51.3 & 14.9 & 8.6 & 12.9 & 12.4 & 48.7 \\
E.U. & 15.1 & 44.9 & 12.7 & 16.9 & 10.3 & 55.1 \\
U.K. & 8.2 & 13.9 & 52.1 & 12.9 & 12.9 & 47.9 \\
Canada & 12.2 & 17.1 & 12.4 & 47 & 11.3 & 53 \\
Japan & 13.6 & 11.1 & 11.4 & 11.9 & 52.1 & 47.9 \\
\hline Contribution & 49.1 & 57.1 & 45.1 & 54.6 & 46.9 & 252.7 \\
TO others & 100.4 & 101.9 & 97.2 & 101.6 & 99 & \\
\hline Contribution & 10.9 & -2.8 & 1.6 & -1 & $\mathbf{5 0 . 5}$ \\
including own & 0.4 & 1.9 & & & \\
\hline Net spillovers & 0.4 &
\end{tabular}

Note: All values are percentages. The number in bold (bottom right corner) represents the total connectedness of the system. Its ijth entry is the estimated contribution to the forecast error variance of economy $i$ coming from innovations to economy $j$. The diagonal elements reveal self-inflicting uncertainty, while all the off-diagonal elements report spillover rates. 